\title{
Centrifuge modeling of mitigation-soil-foundation-structure interaction on liquefiable ground
}

\author{
J. Olarte ${ }^{\mathrm{a}}$, B. Paramasivam ${ }^{\mathrm{a}}$, S. Dashti ${ }^{\mathrm{a}, *}$, A. Liel ${ }^{\mathrm{a}}$, J. Zannin ${ }^{\mathrm{b}}$ \\ ${ }^{a}$ Civil, Environmental and Architectural Engineering, University of Colorado Boulder, 1111 Engineering Drive UBC 428 ECOT 514, Boulder, CO 80309, USA \\ ${ }^{\mathrm{b}}$ Architecture, Civil and Environmental Engineering, Swiss Federal Institute of Technology in Lausanne, Lausanne, Switzerland
}

\section{A R T I C L E I N F O}

\section{Keywords:}

Centrifuge modeling

Soil-structure-interaction

Building performance

Liquefaction mitigation

Densification

Drainage

Reinforcement

\begin{abstract}
A B S T R A C T
Significant progress has been made in recent years toward a better understanding of the liquefaction phenomena. Yet, the combined effects of excess pore pressure generation, permanent soil deformation, and ground shaking, with and without mitigation, on the performance of the soil-foundation-structure system remain poorly understood. Moreover, there is a lack of physical model studies incorporating these important effects for a range of conditions to validate numerical models. This paper presents an experimental study of the performance of 3-story structures with shallow foundations on a saturated soil profile including a thin liquefiable layer. The influence of three different mitigation techniques was evaluated: 1) ground densification; 2) enhanced drainage with prefabricated vertical drains (PVDs); and 3) reinforcement with in-ground structural walls. Densification was observed to slightly reduce excess pore pressures and permanent foundation settlement and tilt, but amplified the demand transferred to the superstructure. Use of PVDs reduced permanent foundation settlement and rotation by reducing the duration of large excess pore pressures, but amplified roof accelerations and flexural drift. The performance of the stiff structural wall depended on the properties of the earthquake motion. During more intense, longer-duration motions, confining the soil and inhibiting flow inside the structural wall led to liquefaction, larger settlements, and larger translational and rotational accelerations on the foundation. In this case, the dissipation of seismic energy through additional foundation movements reduced the moment-rotation demand on the columns. These experimental results emphasize the importance of evaluating the potential tradeoffs of liquefaction mitigation, which may reduce settlement and sometimes tilt, but result in larger transient drifts and damage to the superstructure.
\end{abstract}

\section{Introduction}

The risk of damage to the built environment from liquefaction is significant. As an example, more than $50 \%$ of city of Christchurch in New Zealand was affected by soil liquefaction during the 2011 earthquake, where soil settlement and lateral displacement caused buildings, especially those on shallow foundations, to settle, tilt, deform, and spread laterally [12,9]. Many of these structures were uneconomical to repair and were therefore demolished. To reduce such losses and impacts in future earthquakes, there is need for economical and innovative technologies to improve liquefaction mitigation for design of new structures and retrofit of existing structures.

Significant progress has been made in recent years to understand the phenomenon of liquefaction and its consequences. Nevertheless, the available simplified procedures do not account for: 1) the influence of structures on pore pressure generation, settlement, and accelera- tions in soil; 2) the combined effects of liquefaction-induced permanent soil deformation and ground shaking on the performance and damage potential of buildings; or 3) the effects of liquefaction mitigation on the response of the soil-foundation-structure system. The tradeoffs associated with liquefaction mitigation - which may potentially reduce settlement and tilt, but also amplify ground shaking and shakingrelated damage to the superstructure - are not well understood. Moreover, there is a lack of physical model studies incorporating these important effects that can be used to validate advanced numerical models. These deficiencies prevent the reliable evaluation of the effectiveness of various mitigation techniques to reduce overall risk and improve the performance of the overall system.

In this paper we describe dynamic centrifuge experiments conducted at the University of Colorado Boulder (CU) to evaluate soilfoundation-structure interaction (SFSI) effects on multi-degree-offreedom (MDOF), potentially-inelastic building structures on a liquefi-

\footnotetext{
* Corresponding author.

E-mail addresses: Juan.Olarte@colorado.edu (J. Olarte), Balaji.Paramasivam@colorado.edu (B. Paramasivam), Shideh.Dashti@colorado.edu (S. Dashti), Abbie.Liel@colorado.edu (A. Liel), jacopo.zannin@epfl.ch (J. Zannin).
}

http://dx.doi.org/10.1016/j.soildyn.2017.03.014

Received 10 August 2016; Received in revised form 7 February 2017; Accepted 10 March 2017

Available online 23 March 2017

0267-7261/ (C) 2017 Elsevier Ltd. All rights reserved. 
able deposit with different mitigation techniques. First, we discuss the development and design of the centrifuge models. Then, we examine the results of centrifuge experiments to evaluate the influence of three types of mitigation on the performance of one type of structure and soil profile.

In these experiments, a three-story steel moment-resisting frame structure on a stiff mat foundation was placed on a layered soil profile, including a thin liquefiable layer. The three mitigation types considered were ground densification, prefabricated vertical drains (PVDs), and in-ground structural walls. The response of the mitigation-soil-foundation-structure system was examined in terms of accelerations, pore pressures, and settlements in the far-field and near the structure, as well as the effects of kinematic and inertial interaction near the structures. The effectiveness of the different mitigation techniques was evaluated in terms of permanent and transient foundation settlement and tilt, roof and interstory transient drifts, floor accelerations, and moment-rotation behavior at the column fuses. The experimental results presented in this paper aim to provide insight into the potential tradeoffs of liquefaction mitigation in the context of building performance and damage potential. The two experiments are a part of a larger experimental-numerical study with different building structures, soil conditions, and mitigation strategies.

\section{Background}

\subsection{Assessment of liquefaction consequences on buildings}

Observations of building performance on liquefied sites during previous earthquakes have shown punching settlement, bearing failure, tilt, and lateral shifting of buildings. In the 1964 Niigata (Japan) and the 1990 Luzon (Philippines) Earthquakes, most of the damaged buildings were two to four stories founded on shallow foundations and relatively thick and uniform deposits of clean sand. In contrast, in the 1999 Kocaeli (Turkey) Earthquake, many of the damaged structures were influenced by the liquefaction of thin deposits of silt and silty sand $[40,5,6]$. Building settlement and tilt were found to be directly proportional to its contact pressure and height/width $(H / B)$ aspect ratio [40]. More recently, liquefaction-induced settlements of 1$2 \mathrm{~m}$ and tilts exceeding $2^{\circ}$ were observed near low- to mid-rise structures in the 2011 Christchurch (New Zealand) Earthquake. The uplift forces from groundwater pressures caused floors to bulge upward and foundations to tilt and become damaged [9].

Despite these well-documented case histories, the relation between key ground motion characteristics and the foundation response and damage potential of buildings due to liquefaction, with or without remediation, are not well understood. Buildings that are significantly tilted may need to be demolished and rebuilt, representing a complete loss, although the structural system may be intact. On the other hand, certain types of mitigation may reduce the liquefaction potential and the resulting settlements, but lead to increased shaking and damage to the structural and non-structural systems of the building.

Due to the uncertainties involved in interpreting case histories and the scarcity of instrumental recordings at key locations, physical modeling under controlled conditions can provide additional insights. Several researchers have used reduced-scale shaking table and centrifuge tests to study the response of rigid, shallow model foundations situated atop deposits of saturated, loose to medium dense, clean sand (e.g., [49,30,16,31]). More recently, Dashti et al. [10,11] employed single-degree-of-freedom structural models with realistic fundamental frequencies (as opposed to rigid blocks) on layered liquefiable deposits and investigated the relative influence of various soil and structural parameters on SFSI. Conceptually, the study classified the primary settlement mechanisms as: (a) volumetric types: partial rapid drainage $\left(\varepsilon_{\mathrm{p}-\mathrm{DR}}\right)$ controlled by $3 \mathrm{D}$ transient hydraulic gradients, sedimentation $\left(\varepsilon_{\mathrm{p}-\mathrm{SED}}\right)$ settlements after liquefaction or soil structure break-down, and consolidation $\left(\varepsilon_{\mathrm{p}-\mathrm{CON}}\right)$ volumetric strains as excess pore pressures dissipate; and (b) deviatoric types: partial bearing capacity loss $\left(\varepsilon_{\mathrm{q}-}\right.$ вс) under the static load of structures due to strength loss in the foundation soil resulting in limited punching settlements or tilting of the structure, and soil-structure-interaction (SSI) induced building ratcheting $\left(\varepsilon_{\mathrm{q}-\mathrm{SSI}}\right)$ that occur under the dynamic stresses imposed by structure.

Physical model studies of an entire building-foundation-soil system, particularly with MDOF structures that have a realistic force-deformation behavior are rare. Nonlinear SFSI effects near low- to mid-rise, inelastic structural models on dry sand were investigated in centrifuge by Chen et al. [7] and Mason [32]. The models of building structures had fuses representing hinges of inelastic response. However, the response of MDOF potentially-inelastic structures has not yet been investigated experimentally on liquefiable ground. A detailed evaluation of the demand imposed on the structural elements and their behavior is particularly important when predicting the influence of liquefaction mitigation strategies on building performance.

\subsection{Effectiveness of liquefaction mitigation strategies}

Liquefaction mitigation techniques have been rapidly evolving over the past few decades, and many new methods have been introduced either to prevent liquefaction or to minimize the resulting settlements. However, the reliability and performance of these methods remain unclear, particularly in terms of their utility in reducing building settlement, tilt, and damage, as summarized below.

\subsubsection{Densification methods}

Ground densification decreases liquefaction-induced volumetric settlements and simultaneously increases the stiffness and shear resistance of sand. However, it may not reduce permanent and transient tilt $[10,11]$. It is also expected to amplify foundation accelerations at shorter periods, which may adversely impact the response of the superstructure.

\subsubsection{Drainage methods}

Drains prevent or delay liquefaction by enhancing dissipation of excess pore pressures. Drains are also an effective tool for preventing void redistribution and the formation of a water lens below a lowpermeability crust. Gravel drains have performed well in the past, but this effect has been mainly attributed to increased stiffness and not necessarily enhanced drainage (e.g., $[35,17,19,1])$.

PVDs are hollow, perforated, plastic pipes wrapped in filter fabric that enhance drainage without notable stiffening [18]. In a series of centrifuge tests on slopes with PVDs under seismic loading, Howell et al. [18] showed that PVDs were effective in reducing the duration of high excess pore pressures and hence, reduced vertical and horizontal displacements in most cases. The characteristics of ground shaking significantly influenced the effectiveness of drains and the resulting deformations. Enhanced drainage amplifies volumetric strains due directly to drainage $\left(\varepsilon_{\mathrm{p}-\mathrm{DR}}\right)$, but limits strength loss and deviatoricinduced building movements [11]. Additional physical model studies are required to better evaluate the influence of drainage alone on the performance of shallow-founded structures.

\subsubsection{Reinforcement methods}

In-ground structural walls or equivalent methods that add lateral stiffness to the underlying soil (without additional drainage) are relatively easy to construct around existing structures. Hamada et al. [13]; reported the outstanding performance of footings treated by inground walls during the 1995 Hyogoken-Nanbu (Japan) Earthquake. Centrifuge model tests (e.g., $[1,11,25])$ have also shown that sheet pile walls adjacent to existing structures or slopes may curb settlements by up to $50-60 \%$. However, the influence of in-ground walls on SFSI, tilt, and interstory drift are not understood sufficiently. 


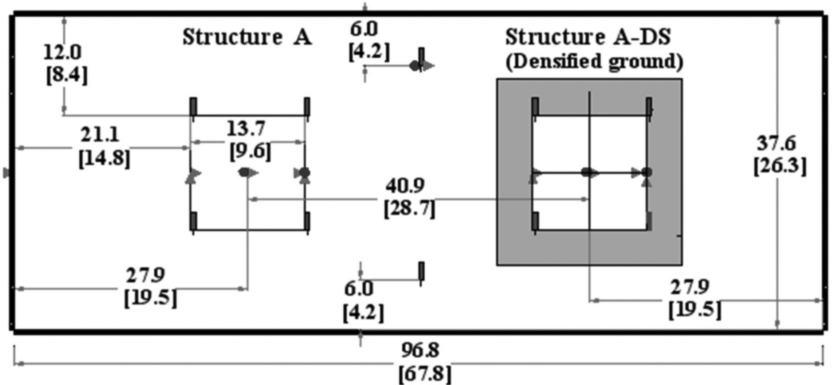

(a)

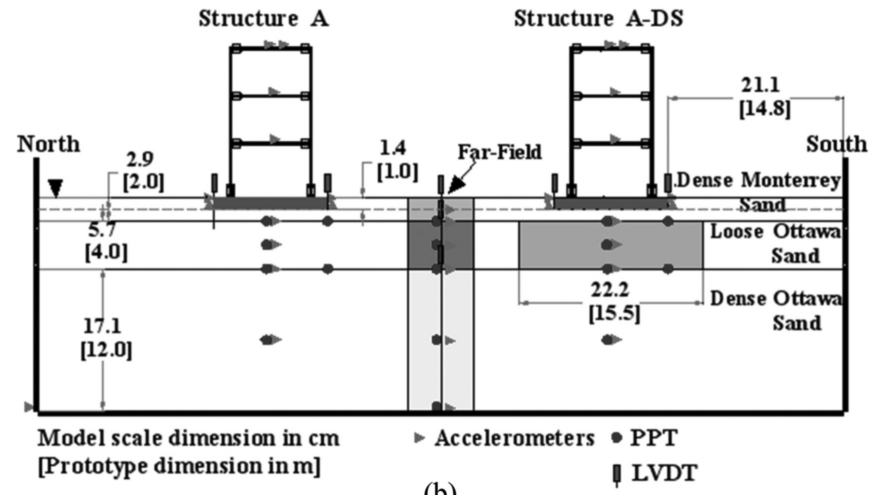

(b)

Fig. 1. Centrifuge model test layout with instrumentation for Test 1: (a) plan view; (b) elevation view.

\section{Design and characterization of experimental components}

A series of centrifuge experiments were designed and conducted at the University of Colorado Boulder's (CU) $400 g$-ton (5.5 m radius) centrifuge facility to evaluate soil-foundation-structure interaction effects and the performance of potentially-inelastic MDOF structures on liquefiable soils. This paper focuses on two experiments with one type of structure and soil profile, but three different liquefaction mitigation strategies: soil densification, enhanced drainage, and soil reinforcement. These experiments are referred to as Test 1 and Test 2. Detailed plan and elevation-view drawings of the model tests and their instrumentation are presented in Figs. 1 and 2. In Test 1, one building was placed with no liquefaction mitigation technique (A), and one was placed on densified ground (A-DS). In Test 2, prefabricated vertical drains (A-DR) and in-ground structural walls (A-SW) were employed as mitigation techniques around the same buildings. The tests were instrumented to record response in the far-field (away from the structures and container boundaries) as well as underneath and on the structures. The model specimens were spun to a centrifugal acceleration of $70 \mathrm{~g}$.

\subsection{Soil profile}

As shown in Figs. 1 and 2, a dense layer of Ottawa sand F65 was dry pluviated to attain a relative density $\left(D_{r}\right)$ of approximately $90 \%$ at the bottom of a flexible-shear-beam (FSB) container constructed of aluminum and rubber. Subsequently, $4 \mathrm{~m}$ of the same sand with $\mathrm{D}_{\mathrm{r}} \approx 40 \%$ was pluviated as the liquefiable material. The liquefiable layer was overlaid by a 2 m-thick layer of Monterrey sand $0 / 30$ with $\mathrm{D}_{\mathrm{r}} \approx 90 \%$, to create a non-liquefiable crust.

The properties of the Ottawa sand were measured by the authors as: maximum void ratio $\left(e_{\max }\right)=0.81$, minimum void ratio $\left(e_{\min }\right)=0.53$, uniformity coefficient $\left(C_{u}\right)=1.56$, specific gravity of solids $\left(G_{s}\right)=2.65$, and vertical hydraulic conductivity $(k)=1.11 \times 10^{-4}$ to $1.41 \times 10^{-4} \mathrm{~m} / \mathrm{s}$ for a relative density $\left(D_{\mathrm{r}}\right)$ of $90 \%$ and $40 \%$, respectively. Course Monterey $0 / 30$ sand was selected as the soil for the non-liquefiable

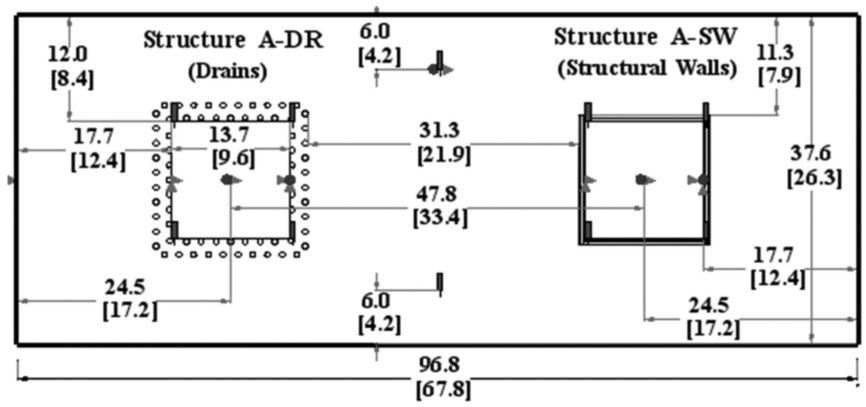

(a)

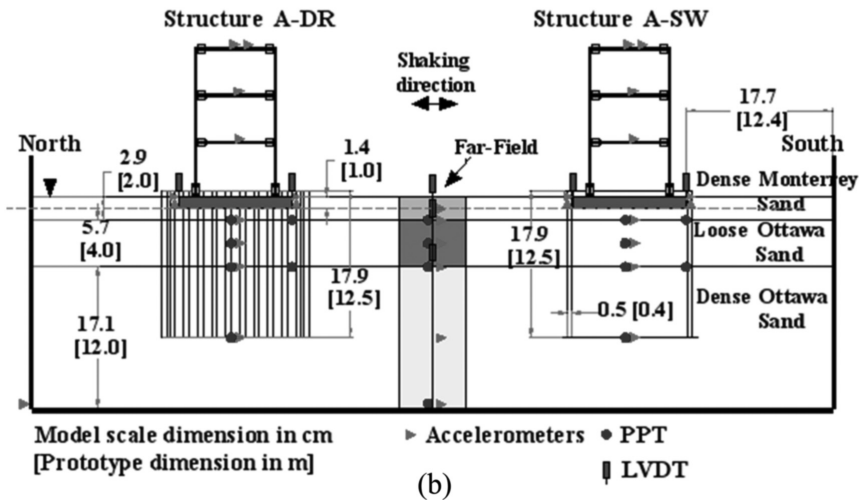

Fig. 2. Centrifuge model test layout with instrumentation for Test 2: (a) plan view; (b) elevation view.

crust. The properties of Monterey sand obtained from the previous researchers were $e_{\max }=0.84, e_{\min }=0.54, C_{u}=1.3, k=5.29 \times 10^{-4} \mathrm{~m} / \mathrm{s}$ $[10,33]$. The layering and thickness of the soil deposits are shown in Fig. 1, which was selected partly based on the container size, the height of the structures, and the available overhead space in centrifuge.

\subsection{Model building structures}

\subsubsection{Design of structural properties}

The footprint of the 3-story model structure was controlled by: 1) the size of the container, 2) the desire to model two isolated structures while minimizing interaction, and 3) the scale factor (centrifugal acceleration). These constraints led to base (foundation) dimensions of $136 \times 136 \mathrm{~mm}$ in model scale $[9.5 \times 9.5 \mathrm{~m}$ prototype scale]. A minimum center-to-center separation of 3-3.5 times foundation width aimed to reduce the interaction between the two buildings, although some dynamic interaction could not be completely avoided experimentally in a small container.

In addition to the constraints on plan dimensions, the design of the superstructure dimensions and properties aimed to satisfy a number of objectives. First, we aimed to design a building with a height to width $(H / B)$ ratio and foundation bearing pressure greater than approximately 1.5 and $70 \mathrm{kPa}$, respectively. These characteristics were desired to amplify soil-structure interaction effects, settlements, and tilting tendencies of the 3-story structure, to more easily evaluate the effectiveness of remediation. In addition, the design of the steel moment frame aimed to be as realistic as possible in terms of modal periods, member sizes, and strength distribution over the height of the building for a building in a high seismic zone. It was critical that the force-deformation response of the component and structure at model scale be consistent with deformation patterns from experiments of fullscale steel beam-column subassemblies. In addition, the reduced "fuse" sections of beams and columns needed to be at least $7.6 \mathrm{~mm}$ wide in model scale to provide enough space to place strain gauges.

Based on these constraints and objectives, the target prototype, 3story structure was designed as a "special" steel moment-resisting 
frame [3] with plan dimensions of $7.1 \times 7.1 \mathrm{~m}$ and heights of $4.5 \mathrm{~m}$ for the 1 st story and $3.9 \mathrm{~m}$ for the second and third stories. Due to the restrictions associated with container size and constructability, the structure was limited to one-bay, with two frame lines resisting seismic loads in the shaking direction. The prototype structure was designed to satisfy the strength and serviceability requirements of ASCE 7-10, considering design and detailing rules for special moment frames [3]. For this purpose, the structure was assumed to be located in a highly seismic area (e.g., Los Angeles), with site classification D, even though the structure was later placed on soft liquefiable ground (Class F). This assumption represented a realistic design scenario after liquefaction mitigation.

For design purposes, the commercially-available structural analysis software package SAP 2000 [48] was used. At each floor, a dead load of $8.9 \mathrm{kPa}$ was used, together with a design live load of $2.3 \mathrm{kPa}$ representing office occupancy. The equivalent lateral force procedure was used to obtain the steel beam and column sections of the target structure in prototype scale, $\mathrm{W} 24 \times 131$. These sections satisfy the strength and drift requirements and meet strong column-weak beam and other detailing requirements for special frames [2,3]. As is the case with many steel frames, the drift limits governed design [14].

The target prototype structure was converted to model scale dimensions and simplified for centrifuge testing as a scaled threedegree-of-freedom (3-DOF) model structure that captures the target modal periods and force-deformation patterns of the prototype structure when spun to $70 \mathrm{~g}$ of centrifugal acceleration $(\mathrm{N}=70)$. Table 1 summarizes the design properties of target prototype structure and the simplified centrifuge model. The design modal periods of the structure are provided in Table 2 . Based on the weight and footprint of the model in centrifuge, the bearing pressure of the structure at the bottom of the foundation was calculated as $80 \mathrm{kPa}$.

A photo of the model structure with its key dimensions is provided in Fig. 3a. The model scale structure was constructed with two moment resisting frames (in the shaking direction) connected through the lumped masses at the floor level in all three stories. The region of maximum moment and potential nonlinearity in the model structure
Table 2

Modal frequencies (periods) of the structure in prototype scale from experiments and numerical simulations.

\begin{tabular}{llll}
\hline & Mode 1 & Mode 2 & Mode 3 \\
\hline $\begin{array}{lll}\text { Design target } \\
\text { ASCE 7-10 }\end{array}$ & $1.8 \mathrm{~Hz}(0.55 \mathrm{~s})$ & - & \\
From SAP 2000 model & $1.9 \mathrm{~Hz}(0.51 \mathrm{~s})$ & $7.7 \mathrm{~Hz}(0.13 \mathrm{~s})$ & $16.7 \mathrm{~Hz}(0.06 \mathrm{~s})$ \\
& & & \\
Experimental & & & \\
Fixed-base & & & \\
Impact test (Mean) & $1.7 \mathrm{~Hz}(0.58 \mathrm{~s})$ & $6.7 \mathrm{~Hz}(0.15 \mathrm{~s})$ & $16.7 \mathrm{~Hz}(0.06 \mathrm{~s})$ \\
$\begin{array}{l}\text { OpenSees nonlinear analyses } \\
\text { Flexible-base }\end{array}$ & $2.0 \mathrm{~Hz}(0.50 \mathrm{~s})$ & $7.7 \mathrm{~Hz}(0.13 \mathrm{~s})$ & $16.7 \mathrm{~Hz}(0.06 \mathrm{~s})$ \\
$\begin{array}{l}\text { Ambient motion } \\
\text { Kobe-L motion }\end{array}$ & $1.8 \mathrm{~Hz}(0.56 \mathrm{~s})$ & $7.1 \mathrm{~Hz}(0.14 \mathrm{~s})$ & $16.4 \mathrm{~Hz}(0.06 \mathrm{~s})$ \\
& $1.5 \mathrm{~Hz}(0.67 \mathrm{~s})$ & $6.7 \mathrm{~Hz}(0.15 \mathrm{~s})$ & $14.5 \mathrm{~Hz}(0.07 \mathrm{~s})$ \\
\hline
\end{tabular}

was designed to occur in reduced sections at beam ends and the column bases in so-called "fuses". The fuses were designed to concentrate response for measurement purposes, as well as represent the expected strong column-weak beam mechanism expected in modern seismicallydesigned frames. A solid rectangular cross-section made of steel was selected for fuses. The size of this section was determined by scaling the design moment of inertia of beams and columns in prototype scale, since these elements deform primarily in flexure. Member area similitude was sacrificed because it was not possible to maintain perfect scaling of moment of inertia and member area simultaneously because of the scaling laws [45].

The fuses - shown in Fig. 3b - were designed to be replaceable to improve testing efficiency. The replaceable fuse units consisted of a $6.35 \mathrm{~mm}$-long dogbone shape with vertical steel plates welded at both ends. These vertical plates were bolted to complementary vertical plates on the beam and column sections. The rectangular beam and column sections were selected to be larger than the fuses to avoid nonlinearity outside fuses. The lumped masses were bolted to the beams on each floor.

Table 1

Properties of structures as designed and simplified for centrifuge testing.

\begin{tabular}{|c|c|c|c|}
\hline & \multirow[t]{2}{*}{ Target structure in prototype scale } & \multicolumn{2}{|c|}{ Simplified centrifuge model structure } \\
\hline & & Prototype scale & Model scale $(\mathrm{N}=70)$ \\
\hline Number of stories & 3 & 3 & 3 \\
\hline Seismic structural system & SMRF $^{\mathrm{a}}$ & SMRF & SMRF \\
\hline Height above the ground (m) & 12.5 & 12.5 & 0.178 \\
\hline Footprint dimension $(\mathrm{m})$ & $7.1 \times 7.1^{\mathrm{b}}$ & $7.1 \times 7.1$ & $0.101 \times 0.101$ \\
\hline Base shear $(\mathrm{kN})$ & $\begin{array}{l}\text { Design: } 289^{c} \\
\text { Yield: } 3804^{\mathrm{d}}\end{array}$ & Yield: $6425^{\mathrm{e}}$ & Yield: 1.31 \\
\hline Building weight $(\mathrm{kN})$ & 1355.2 & $4319.1^{\mathrm{f}}$ & 0.013 \\
\hline Beam and column section at fuse location & W24 $\times 131^{\mathrm{g}}$ With flange width $=326.6 \mathrm{~mm}$ and depth $=621.8 \mathrm{~mm}$ & Solid section $532 \times 315 \mathrm{~mm}$ & Solid section7.6×4.5 mm \\
\hline Beam and column section elsewhere & Same as fuse & Solid section ${ }^{\mathrm{h}} 1106 \times 336 \mathrm{~mm}$ & Solid section $15.8 \times 4.8 \mathrm{~mm}$ \\
\hline Nominal steel strength used in design (MPa) & 372 & $372^{\mathrm{i}}$ & 372 \\
\hline Yield steel strength (Mpa) & $\mathrm{N} / \mathrm{A}$ & $588^{j}$ & 588 \\
\hline Foundation type & Mat & Mat & Mat \\
\hline Foundation size (m) & $9.5 \times 9.5^{\mathrm{b}}$ & $9.5 \times 9.5$ & $0.136 \times 0.136$ \\
\hline Foundation embedment (m) & 1 & 1 & 0.014 \\
\hline Foundation contact pressure $(\mathrm{kPa})$ & 75 & 80 & 80 \\
\hline
\end{tabular}

${ }^{a}$ SMRF - Special steel moment resisting frame.

${ }^{\mathrm{b}}$ Based on the constraints of centrifuge model.

${ }^{\mathrm{c}}$ Design base shear computed from ASCE 7-10.

d Yield base shear estimated from 2D nonlinear pushover analyses on the structure in OpenSees.

e Yield base shear computed from SAP2000.

${ }^{\mathrm{f}}$ Area similitude distortion and the bigger beam and column sections outside the fuse provided a weight higher than the target design building.

${ }^{\mathrm{g}}$ Steel section obtained to satisfy the strength and drift requirement and used for both beams and columns.

${ }^{\mathrm{h}}$ Although the prototype structure uses a constant cross section for beams and columns, we use a larger section for regions outside the fuse in the model structure to ensure concentration of damage at fuses and for ease of constructability.

${ }^{i}$ Strength obtained from the manufacturer data sheet.

${ }^{\mathrm{j}}$ Yield strength interpreted from the beam-column component tests. 


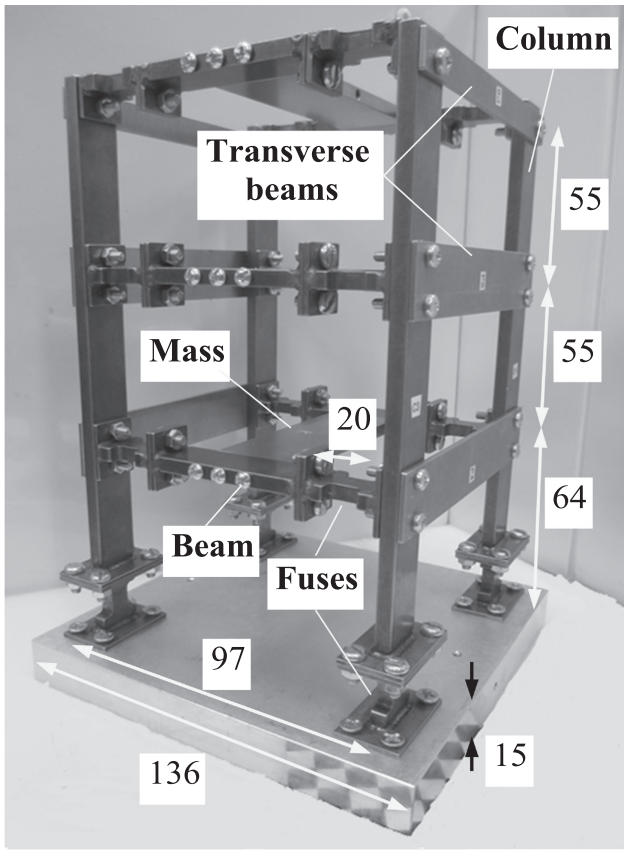

(a)

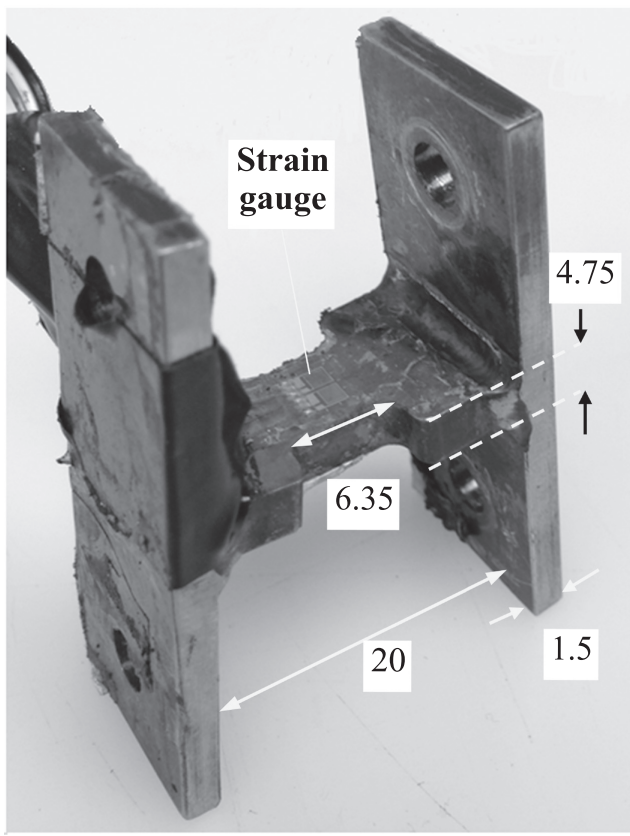

(b)

Fig. 3. (a) Simplified, scaled, 3-DOF moment frame structure used in centrifuge; and (b) replaceable fuse used at beam and column ends. All dimensions listed are in model scale in $\mathrm{mm}$.

The mat foundation (detailed in Table 1) was constructed using aluminum for practicality and to simulate the approximate unit weight of reinforced concrete. Foundation embedment ( $1 \mathrm{~m}$ in prototype scale) was estimated to ensure overall stability of the structure after liquefaction, avoiding complete bearing capacity failure.

\subsubsection{Characterization of structural properties}

Once fabricated, the moment-rotation behavior of fuses was characterized both under static monotonic and cyclic loading through

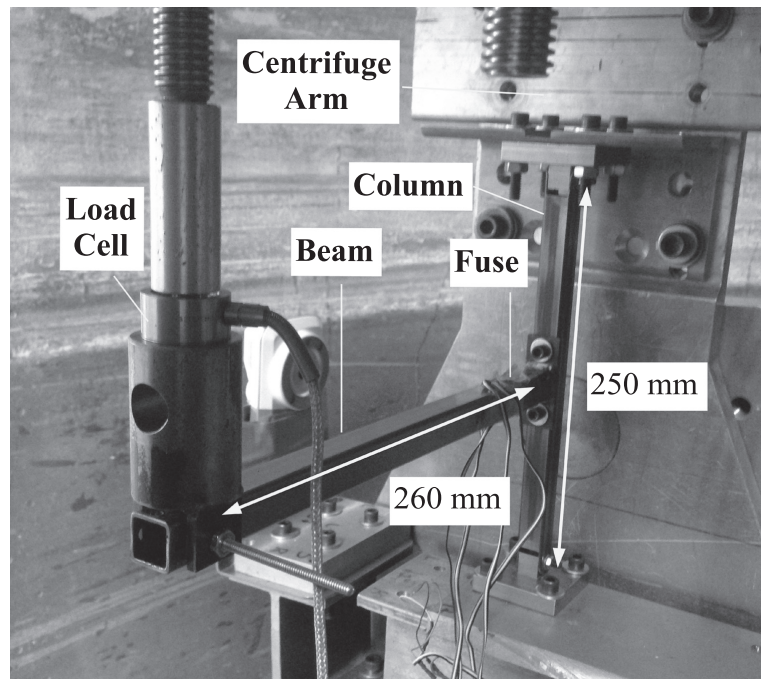

Fig. 4. Beam-column component testing arrangements and details inside the medium centrifuge platform.

component tests and compared with the behavior expected for fullscale steel subassemblies. Subsequently, the constructed 3-story model superstructures were subject to impact vibration tests, to verify their modal periods under fixed-base conditions. These results were used to calibrate nonlinear numerical simulations of the building, which could be used to predict the structure's nonlinear pushover response.

\section{Fuse behavior}

Beam-column component tests were conducted to characterize the moment-rotation behavior of the designed and fabricated fuse sections, which control the force-displacement behavior of the structure as a whole. Eight pseudo-static tests, 4 monotonic and 4 cyclic, at centrifugal accelerations of $1 \mathrm{~g}$ and $70 \mathrm{~g}$ were conducted using the smaller, $15 g$-ton centrifuge facility at CU. Fig. 4 shows the beam-column component test setup with the replaceable fuse inside the centrifuge platform beam-column connection. The column ends were pinned and free to rotate, representing a beam-column subassembly test from midstory to mid-story. To perform the monotonic tests, a slow monotonically-increasing downward displacement was applied to the end of the beam. The cyclic test followed the ATC-24 loading protocol for cyclic testing of steel components [26]. The vertical displacement and force was measured using an internal LVDT and load cell attached to the actuator arm. Strain gauges were placed on both sides of the fuse, as shown in Fig. 3b, in a half-bridge configuration.

The mean $(\mu)$ and coefficient of variation $(\overline{C O V})$ of yield moment and yield rotation of fuses were estimated in model scale (for all eight tests) as follows: 1) $\mu=16.9 \mathrm{~N} \mathrm{~m}$ and $\overline{C O V}=0.16$ for yield moment; and 2) $\mu=0.032 \mathrm{rad}$ and $\overline{C O V}=0.12$ for yield rotation. From the results of component tests, the mean yield strength of steel was computed as $588 \mathrm{MPa}$, which was approximately $60 \%$ higher than the nominal strength specified by the manufacturer at the time of design, as reported in Table 1. This difference in steel yield strength led to a stronger fuse behavior than anticipated or considered in design.

Fig. 5 shows the moment-rotation behavior of fuses obtained during selected monotonic and cyclic tests at a centrifugal acceleration of $1 \mathrm{~g}$ and $70 \mathrm{~g}$. The fuse moment-rotation behavior was similar under a centrifugal acceleration of $1 g$ (Fig. 5a) and $70 g$ (Fig. 5b), as the material properties were pressure-independent. The initial stiffness was also similar between the different tests. However, the yield strength in monotonic tests was less than the cyclic tests, which indicates hardening due to each cycle of loading (particularly at $1 g$ ). This is consistent with the expected cyclic strain hardening behavior of steel from previous full-scale tests [27].

Fig. 6 compares the moment-rotation behavior of full-scale beam- 


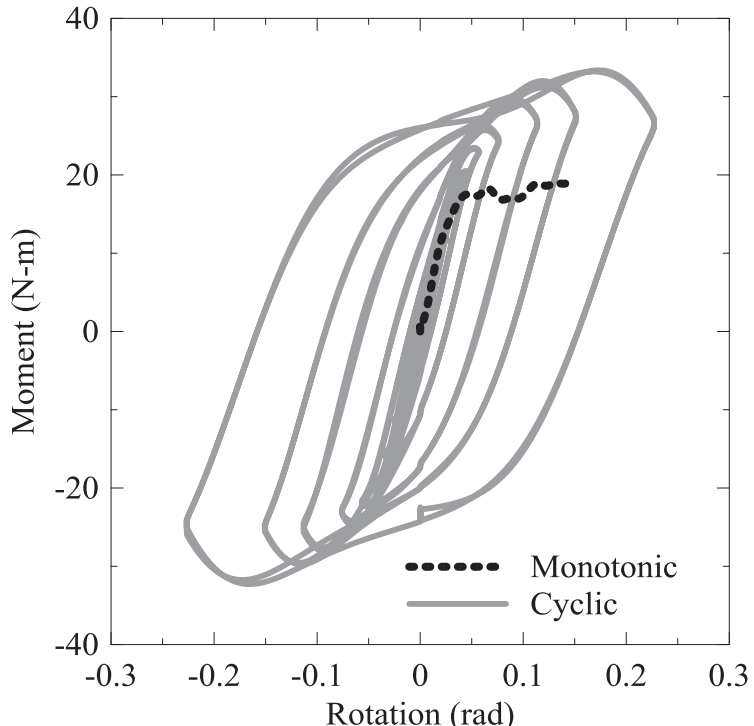

(a)

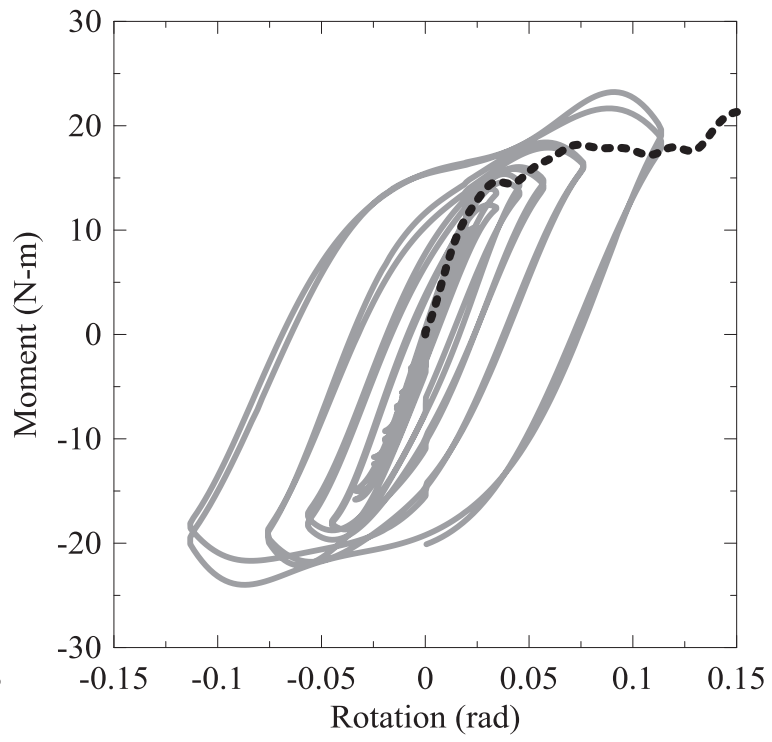

(b)

Fig. 5. Monotonic and cyclic test of structural fuse at a centrifugal acceleration of: (a) $1 g$; and (2) $70 g$. Results are shown for one test in each case, although more tests were conducted.

column subassemblies from the literature with the model scale test presented in this paper under monotonic and cyclic loading. The moment is normalized with the corresponding yield moment, in order to compare the behavior between the tests at different scales. The cyclic full-scale test conducted by Tsai [46] had similar reduced beam sections (RBS) to the fuses in the model scale test. The post-yield hardening behavior observed during the monotonic and cyclic tests were consistent between the model scale and full-scale tests. However, the comparison showed that our beam-column model was more flexible than the full-scale tests. This difference is mainly due to the flexibility governed by the welding and bolting joints (Fig. 3b). In addition, model scale tests were conducted for rotations higher than that of the fullscale test to study the post-yield behavior of the assembly. In general, we conclude that it was possible to replicate the key characteristics of full-scale steel beam-column subassemblies were successfully achieved in a simplified, scaled model.

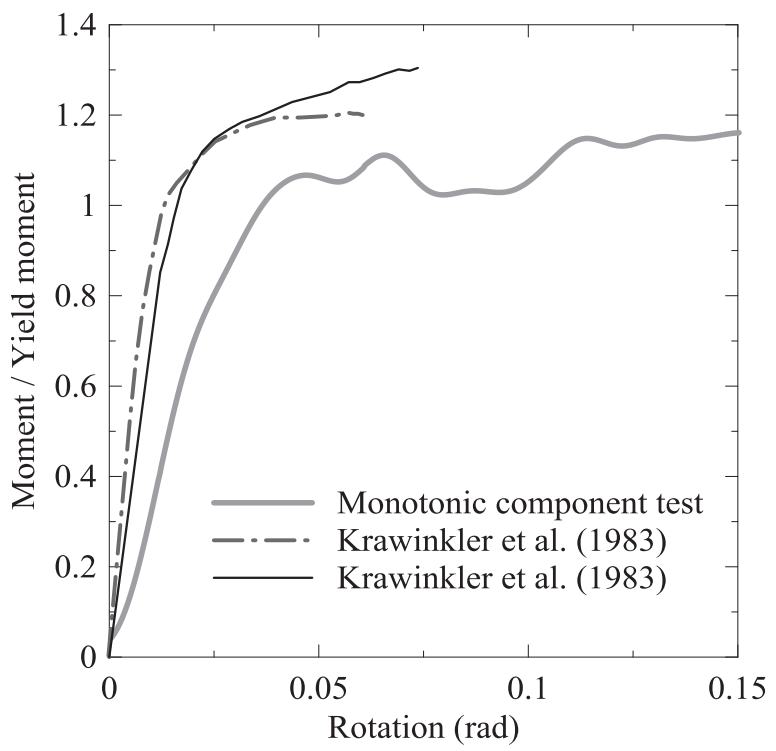

(a)
Free-vibration impact tests

Impact tests were conducted on the structures after fabrication to characterize their natural periods and damping. During the impact test, the foundation of the model structure was firmly fixed on the floor. The impact pulses were applied to the roof of the structure in the direction designed to resist shaking. The transfer function (TF) of accelerations at the roof relative to foundation showed peak amplification at three distinct periods or frequencies, which were interpreted as fixed-base modal periods or frequencies of the structure $\left(T_{S T}\right.$ or $\left.f_{S T}\right)$. The first three modal periods obtained from the impact tests (mean of three trials) agreed well with the design values estimated from the building code and obtained from the SAP2000 model, as detailed in Table 2. The small discrepancies between the design and impact test values were due to the additional mass of instruments and flexibility from bolted and welded connection at the beam and column ends not considered in design. These values were also compared with the flexible-base

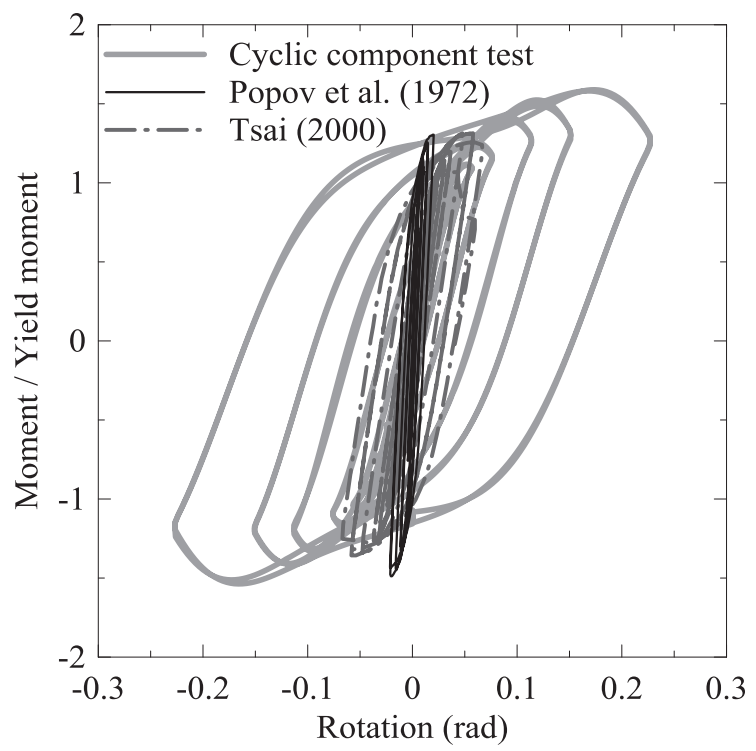

(b)

Fig. 6. Comparison of moment-rotation behavior of beam-column component test conducted here with full scale tests under: (a) monotonic; and (b) cyclic loading [39]. 
fundamental period of the structure in centrifuge during different motions, as summarized in Table 2. A damping ratio of the model structure was measured with a mean value $2.8 \%$ (standard deviation of $0.18 \%$ ) using the logarithmic decrement method [8].

\section{Nonlinear simulations of structure in OpenSees}

A 2-dimensional (2D) fixed-base representation of one of the frames of the scaled structure was simulated in the finite element program OpenSees as a means of verifying the design and evaluating the response of the structures. The beams and columns of the structure were modeled as elastic beam-column elements. The fuses were represented by nonlinear zero length springs, using the material model developed by Ibarra et al. [20]. The material strength obtained from beam-column tests was used to characterize the moment strengths, and the stiffness of these springs was calibrated to beam-column component tests discussed above to represent the flexibility of the welded connections in the fuses. The parameters needed to model the nonlinear response of the fuses were determined from empirical equations developed by Lignos and Krawinkler [28], which predict deformation capacity and degradation properties for full-scale steel specimens based on section geometry. These properties were based on the sections chosen for the full-scale prototype structure (Table 1).

Modal analyses were performed to identify the fixed-base modal periods of the structure, which compared well with SAP analyses and impact test results, as shown in Table 2. Nonlinear static pushover analyses with a triangular load distribution were also conducted on the model structure, which could be compared with the centrifuge test results.

Fig. 7 shows the base shear versus roof drift behavior of the structure obtained from pushover analyses. Fig. 7 indicates a linearelastic structure behavior until a roof drift ratio of $Y_{1}=0.018$. After this point, the first and second floor beams reached their yield moment capacity $\left(\mathrm{Y}_{2}\right)$; subsequently, the springs at the column ends reached their yield moment at $Y_{3}$ and, finally, the springs at the beams at the roof yielded (point $\mathrm{Y}_{4}$ ). A softening response was observed after a roof drift due to the softening of the nonlinear springs at the first and second story beams. These pushover results also showed that the yield base shear of the model structure was much higher than the design value (Table 1). This behavior was due to the difference in the actual yield strength of steel compared to the manufacturer's reported value, as well as code requirements other than strength that controlled the design (such as drift limits). As a result, yielding of the structure was not expected during the centrifuge experiments presented. However,

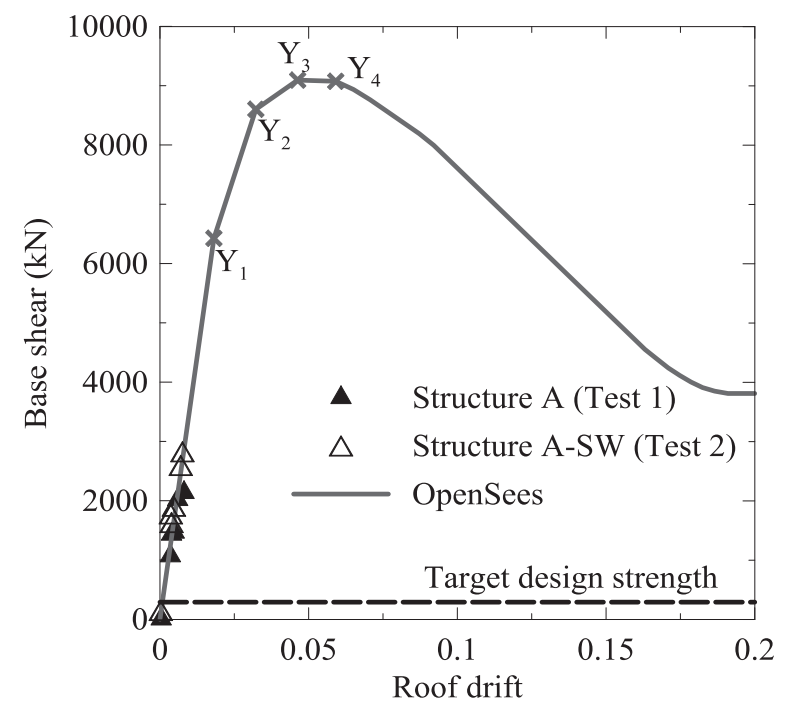

Fig. 7. Base shear versus roof drift from pushover analyses compared to the centrifuge results for all ground motions. the deformation pattern observed during the nonlinear pushover analysis was similar to the larger-scale pushover test on a codedesigned MDOF steel structure by Lignos et al. [29]. Further, in later experiments we used a material weaker than steel (i.e., nickel) to represent the response of inelastic structures.

\subsection{Mitigation strategies}

\subsubsection{Ground densification}

The soil under Structure A-DS in Test 1 (Fig. 1b) was densified, while the adjacent loose soil was still susceptible to liquefaction. Since the soil profile in the presented experiments had a relatively thin liquefiable layer $(4 \mathrm{~m})$, the improvement depth covered the entire thickness of the looser layer of Ottawa sand. The lateral extent of densification beyond the foundation was selected as one-half of the improved depth, as proposed by Japanese Geotechnical Society (JGS) [22]. Hence, the prototype plan view dimensions of the densified zone underneath the structure were selected as $222 \times 222 \mathrm{~mm}$ in model scale [15.5 $\times 15.5 \mathrm{~m}$ prototype], as shown in Fig. 8 a. Soil densification under Structure A-DS was constructed using a temporary aluminum box, as shown in Fig. 8a. The soil layer inside the aluminum box was dry pluviated to achieve a relative density $D_{r} \approx 90 \%$. The densification box was slowly removed after pluviation.

\subsubsection{Prefabricated vertical drains}

The key parameters in designing the PVDs for Structure A-DR were drain internal diameter and center-to-center spacing. These parameters were designed to ensure that the excess pore pressures were less than a threshold value for the design earthquake. The threshold value was expressed in terms of excess pore pressure ratio $\left(\mathrm{r}_{\mathrm{u}}=\Delta \mathrm{u} / \sigma_{\mathrm{vo}}{ }^{\prime}\right.$, where $\Delta \mathrm{u}$ is the excess pore water pressure and $\sigma_{\mathrm{vo}}{ }^{\prime}$ is the initial vertical effective stress at a given depth, considering the induced pressure variation with depth near the structure). Seed and Booker [41] suggested a peak $r_{u}$ of 0.6 as the design threshold. In this study, a drain pipe internal radius of $1.58 \mathrm{~mm}$ in model scale $[111 \mathrm{~mm}$ in prototype] was selected. This drain diameter is considerably larger than what would be used in reality. However, practicality considerations in construction of drains in the reduced scale model governed the selection of drain size. The prototype drains were assumed to have rectangular orifice slots.

To select the center-to-center spacing between drains, the finite element tool FEQdrain developed by Pestana et al. [38] was first employed. The results were subsequently compared with the drain design charts proposed by JGS [22]. FEQdrain was used to predict $r_{u}$ as a function of drain spacing and cycle ratio using the drain and geotextile properties shown in Table 3. Cycle ratio is defined as the ratio of the number of equivalent cycles of the ground motion to the number of cycles required to initiate liquefaction (defined as $r_{u}=1.0$ ) in the loose liquefiable soil layer. FEQdrain analyses were conducted for a design ground motion that had an effective duration of $15 \mathrm{~s}$ and cycle ratios of 1,2 , and 3 . The resulting excess pore pressure ratios were predicted radially outward from the center of the drain at the elevations corresponding to the top, middle, and bottom of the liquefiable soil layer. The peak $r_{u}$ computed at the top of the liquefiable layer reached 0.6 at a radial distance of $0.6 \mathrm{~m}$ away from the center of the drain. As a result, a drain center-to-center spacing of $1.2 \mathrm{~m}$ around the foundation was desired.

Table 3 summarizes the PVD properties as designed and used in centrifuge around the perimeter of the structure. The PVDs designed based on the FEQdrain analyses in prototype units were scaled following the centrifuge scaling laws. The model drain pipes were made of santoprene tubes of internal diameter $3.2 \mathrm{~mm}$ and length $178.6 \mathrm{~mm}$. The circular orifices allowing water inflow to the drain pipe were drilled manually through the drain pipe surface to approximate the rectangular orifices in the prototype PVD. These holes were approximately $0.71 \mathrm{~mm}$ in diameter, placed at a spacing of $5 \mathrm{~mm}$ 


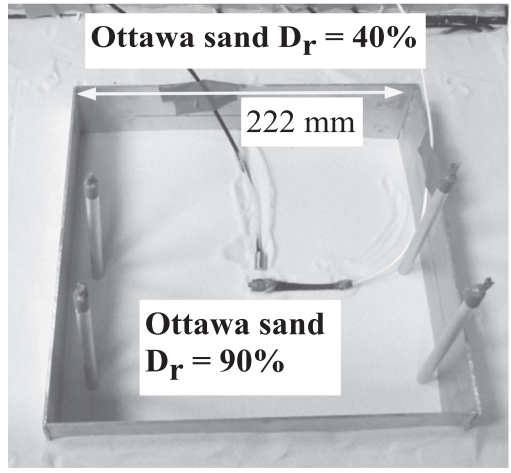

(a)

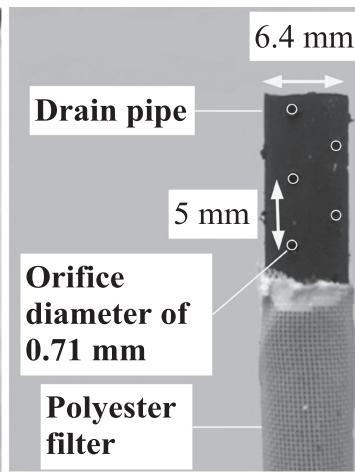

(b)
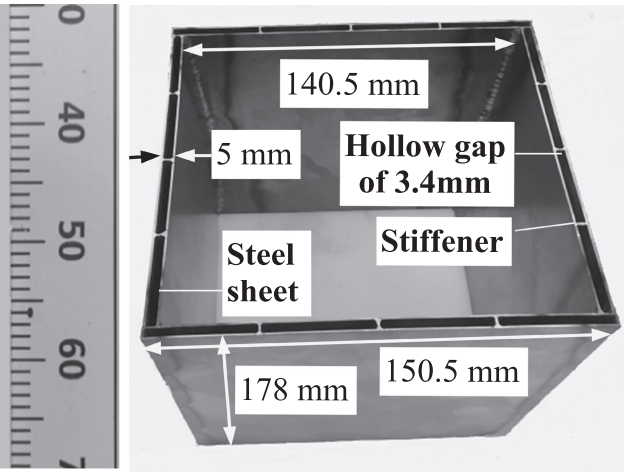

(c)

Fig. 8. Pictures of mitigation techniques implemented around Structures A-DS, A-DR, and A-SW: (a) densification setup during model preparation; (b) PVD pipe with its filter; and (c) in-ground hollow steel structural wall.

Table 3

Design properties of prefabricated vertical drains.

\begin{tabular}{|c|c|c|c|}
\hline \multirow[t]{2}{*}{ Properties } & \multirow{2}{*}{$\begin{array}{l}\text { Target prototype } \\
\text { design using } \\
\text { FEQdrain }\end{array}$} & \multicolumn{2}{|c|}{$\begin{array}{l}\text { Simplified design in } \\
\text { centrifuge }\end{array}$} \\
\hline & & $\begin{array}{l}\text { Prototype } \\
\text { scale }\end{array}$ & Model scale \\
\hline \multicolumn{4}{|l|}{ Drain Pipe } \\
\hline Material & Plastic tube & $\begin{array}{l}\text { Santoprene } \\
\text { tube }\end{array}$ & $\begin{array}{l}\text { Santoprene } \\
\text { tube }\end{array}$ \\
\hline $\begin{array}{l}\text { Internal radius, a } \\
\text { (m) }\end{array}$ & 0.111 & 0.111 & 0.0016 \\
\hline $\begin{array}{l}\text { Depth of } \\
\text { treatment, h } \\
\text { (m) }\end{array}$ & 12 & 12 & 0.172 \\
\hline Area ratio (\%) & 1.5 & 2.1 & 2.1 \\
\hline \multicolumn{4}{|l|}{ Geotextile } \\
\hline $\begin{array}{l}\text { Material } \\
\text { Type }\end{array}$ & $\begin{array}{l}\text { Polypropylene } \\
\text { woven }\end{array}$ & $\begin{array}{l}\text { Polyester } \\
\text { woven }\end{array}$ & $\begin{array}{l}\text { Polyester } \\
\text { woven }\end{array}$ \\
\hline $\begin{array}{l}\text { Aperture size } \\
\quad(\mathrm{mm})\end{array}$ & $0.21^{*}$ & 0.178 & 0.178 \\
\hline $\begin{array}{l}\text { Permittivity (1/ } \\
\quad \mathrm{sec})\end{array}$ & $0.28^{*}$ & - & - \\
\hline Drain Pattern & - & $\begin{array}{l}\text { Triangular } \\
\text { pattern }\end{array}$ & $\begin{array}{l}\text { Triangular } \\
\text { pattern }\end{array}$ \\
\hline $\begin{array}{l}\text { Center to center } \\
\text { spacing, } S(\mathrm{~m})\end{array}$ & - & 1.2 & 0.017 \\
\hline
\end{tabular}

" Values specified by the manufacturer.
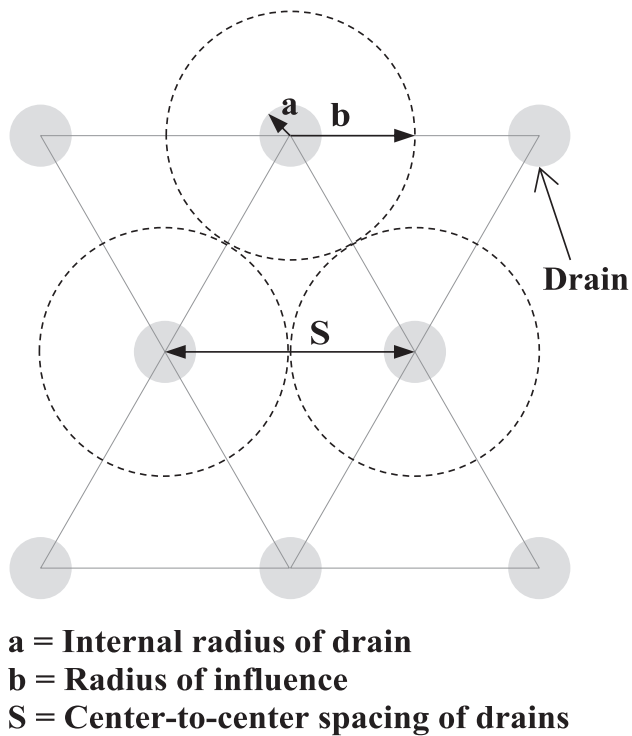

Fig. 9. Triangular arrangement of PVD and its the effective drainage area and spacing. along the length of the tube from the surface to the middle of the bottom dense layer of Ottawa sand. Each drain pipe had an area ratio of $2.1 \%$, which is defined as the ratio of total orifice area to the surface area of the drain pipe. Each drain pipe was subsequently wrapped with a precision-woven polyester mesh that had an aperture opening size of $0.178 \mathrm{~mm}$ to avoid clogging, selected based on the particle size distribution of Ottawa sand. These model drains with geotextile were installed in a triangular pattern around the foundation of Structure ADR at a spacing of $17 \mathrm{~mm}$ in model scale [1.2 $\mathrm{m}$ prototype], as shown in Fig. 9. Drains with geo-textile filters (Fig. 8b) were attached to a temporary frame, which was constructed to maintain the center-tocenter spacing of drains during pluviation.

The spacing of drains computed from FEQdrain was subsequently compared with the design charts proposed by JGS [22], based on the work of Seed and Booker [41] and Onuce et al. [37]. The horizontal hydraulic conductivity of PVDs without any lateral confinement was measured after drain fabrication as $0.13 \mathrm{~m} / \mathrm{s}$ in a constant head permeability test performed by the authors. The horizontal hydraulic conductivity of Ottawa sand with $\mathrm{D}_{\mathrm{r}} \approx 40 \%$ was measured from the constant head test as $3.77 \times 10^{-4} \mathrm{~m} / \mathrm{s}$. Assuming a ground motion duration of $15 \mathrm{~s}$, a cycle ratio of 3 , and a threshold $r_{u}$ of 0.6 , a maximum drain spacing of $1.9 \mathrm{~m}$ (in prototype scale) was obtained from the design chart. The spacing obtained from the FEQdrain analyses during design was $1.2 \mathrm{~m}$, which was conservative (smaller spacing) compared to the design chart.

\subsubsection{Structural walls}

In this study, liquefaction around Structure A-SW was mitigated by constructing stiff structural walls (i.e., sheet pile walls) around the perimeter of the footing. Fig. $8 \mathrm{c}$ shows a picture of the structural wall and its model scale dimensions. The plan view dimensions of structural walls were designed to be close to the footing area, with a gap of $2.25 \mathrm{~mm}$ in model scale [157 mm prototype] between the wall and the edge of the foundation in model scale, to minimize movement of soil from underneath. The walls were not connected to the foundation, in order to avoid simulating deep foundations.

The primary goal was to minimize shear type deformations in the underlying soil and gain insight into the effects of very stiff walls and reinforcement on structure's performance. Replicating the sectional geometry of full-scale sheet pile walls (e.g., circular or u-shaped steel sections) was not practical in a scaled model due to constructability and welding requirements. Therefore, the sectional geometry of each structural wall around the perimeter of the foundation was designed with simple and single hollow rectangular sections of dimensions shown in Fig. 8c. The height of the wall was selected as $178 \mathrm{~mm}$ in model scale [12 $\mathrm{m}$ in prototype], providing reinforcement from the soil surface through the middle of the lower dense sand (Fig. 2b).

The hollow rectangular sections were constructed by welding steel 
Table 4

Ground motion properties as recorded at the base of the container in centrifuge Test 1 (same sequence of motions was applied in Test 2).

\begin{tabular}{|c|c|c|c|c|c|c|c|}
\hline $\begin{array}{l}\text { Ground Motion } \\
\text { No. }\end{array}$ & $\begin{array}{l}\text { Ground Motion } \\
\text { ID }\end{array}$ & Event & Station & PGA (g) & $\begin{array}{l}\text { Significant Duration, } D_{5-} \\
95(s)\end{array}$ & $\begin{array}{l}\text { Mean Period, } T_{m} \\
\text { (s) }\end{array}$ & $\begin{array}{l}\text { Arias Intensity, } I_{a}(m / \\
\text { s) }\end{array}$ \\
\hline 1 & Joshua-L & 1992 Landers & Joshua Tree & 0.02 & 32 & 0.9 & 0.004 \\
\hline 2 & Kobe-L & 1995 Kobe & Takatori & 0.33 & 14 & 0.9 & 1.6 \\
\hline 3 & Joshua-H & 1992 Landers & Joshua Tree & 0.45 & 27 & 0.7 & 6.8 \\
\hline 4 & Northridge & 1994 Northridge & Newhall-WPC & 0.51 & 16 & 1.1 & 3.9 \\
\hline 5 & Kobe-M & 1995 Kobe & Takatori & 0.79 & 29 & 0.9 & 8.0 \\
\hline 6 & Kobe-H & 1995 Kobe & Takatori & 0.69 & 29 & 0.9 & 8.5 \\
\hline
\end{tabular}

sheets of thickness $0.8 \mathrm{~mm}$ on each side with a gap of $3 \mathrm{~mm}$ maintained with stiffeners, as shown in Fig. 8c. The four hollow rectangular sections were welded on their two sides to each other at $90^{\circ}$ to form a box or skirt around the foundation. A sealant was later applied at the top and bottom faces of the hollow section to avoid upward flow through the hollow gap.

The selected hollow section with intermediate stiffeners achieved a moment of inertia of $1677.3 \mathrm{~mm}^{4}$ model scale [0.04 $\mathrm{m}^{4}$ prototype], which exceeded that of typical steel sheet pile walls available in the USS [47] (e.g., $2.9 \times 10^{-3} \mathrm{~m}^{4}$ in prototype scale for a sheet pile wall using $\mathrm{z}$ sections). By using a stiffer in-ground wall, shear type deformations could be minimized in the underlying soil to the extent possible. The design also ensured that the unit weight of the wall was similar to that of soil, to avoid its relative settlement or uplift during earthquake loading.

\subsection{Model saturation}

After model preparation, the specimens with soil and structures in place were covered with a sealed cap and saturated with a hydroxypropyl methylcellulose solution that had a viscosity of $64 \mathrm{cSt}$ [43], 70 times greater than that of water, to satisfy the dynamic scaling laws [45]. A computercontrolled saturation system was designed and implemented to improve the quality and rate of saturation, similar to that proposed by Stringer and Madabhushi [44]. Initially, the soil model was flushed with $\mathrm{CO}_{2}$ from the bottom of the container for about one hour, after which the soil model and the fluid tank were both kept under vacuum. The fluid tank was placed on a scale and its vacuum level was subsequently controlled automatically to maintain a safe and constant flow rate below that required for flow-induced liquefaction (in this case $19 \mathrm{~g} /$ minute, based on Stringer and Madabhushi [44]). It took approximately $36-40 \mathrm{~h}$ to complete the saturation of the model for each test.

\subsection{Ground motions}

The saturated soil specimens with model structures were spun to a centrifugal acceleration of $70 \mathrm{~g}$ and subject to a series of 1D horizontal earthquake motions in flight using a servo-controlled hydraulic shake table [24]. These motions were scaled versions of horizontal component of recorded earthquake motions, selected to cover a range of characteristics in terms of amplitude, frequency content, and duration. The $1992 \mathrm{Mw} 7.3$ Landers Earthquake recorded at the Joshua Tree station was selected because of its longer duration and slower rate of energy build-up relative to the other records. The $1995 \mathrm{Mw} 6.9$ Kobe (Japan) Earthquake recorded at the Takatori station had a more rapid build-up of energy. Both motions were applied multiple times at different intensities. Lastly, the 1994 Northridge Mw 6.7 earthquake recorded at the Newhall-WPC station is a near-fault record with a significant velocity pulse. The letter after hyphen of each ground motion indicates the intensity of the motion (L: Low, M: Moderate, $\mathrm{H}$ : High). Table 4 shows the sequence of six earthquake motions applied at the base of the model container, and Fig. 10 shows the acceleration response spectra (5\% damped) and Arias intensity time histories of the base motions achieved in centrifuge.

\subsection{Instrumentation and measurements}

Each of Tests 1 and 2 (Figs. 1 and 2) were instrumented with 91

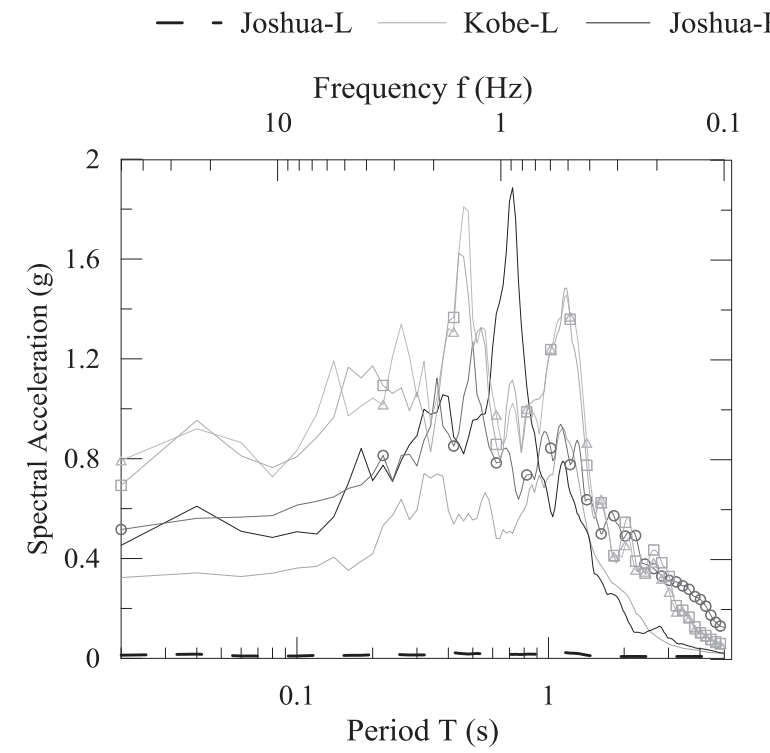

(a)

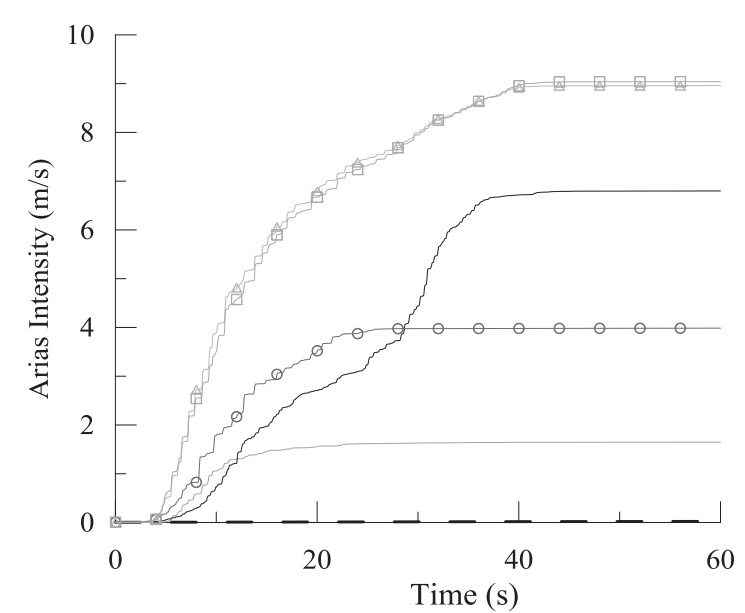

(b)

Fig. 10. Container base ground motions achieved in centrifuge during Test 1 showing: (a) acceleration response spectra (5\% damped); and (b) Arias Intensity time histories. Small differences in achieved motions were observed between Tests 1 and 2 . 
Acceleration $\longrightarrow$ Excess Pore Pressure $\quad-\cdot r_{u}=1$

KOBE-L
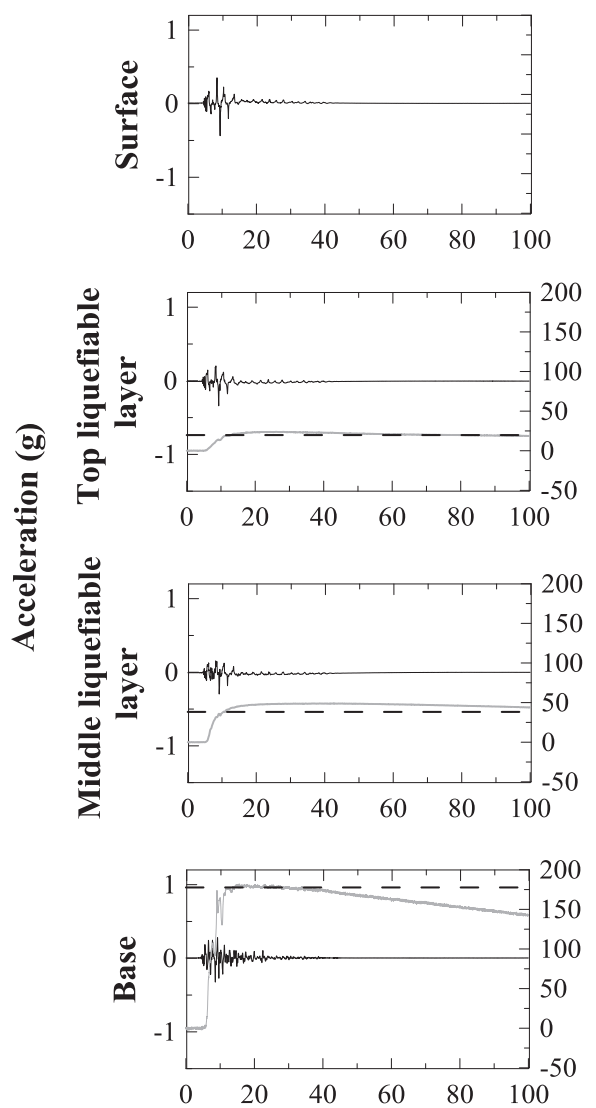

Time (s)
JOSHUA-H
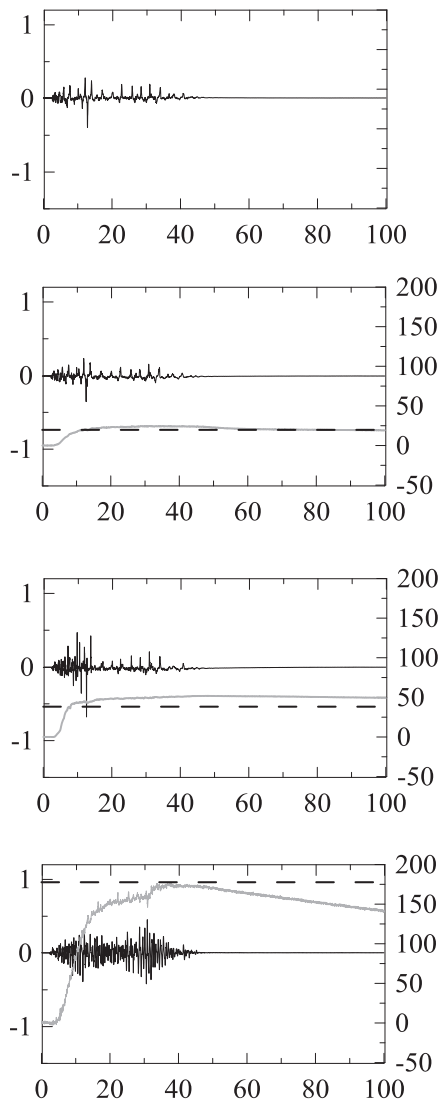

Time (s)
NORTHRIDGE
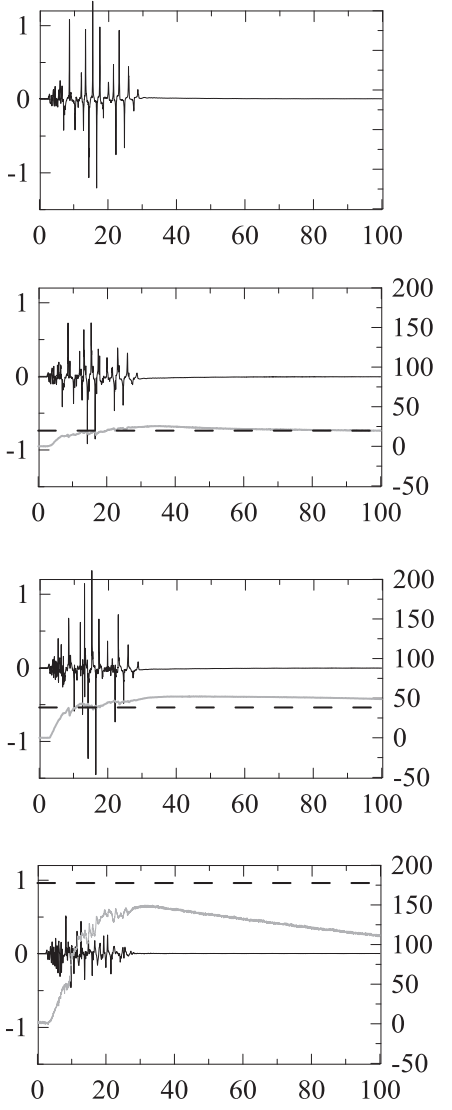

Time (s)

Fig. 11. Far-field acceleration and excess pore pressure time histories during Kobe-L, Joshua-H, and Northridge events in Test 1.

sensors, including accelerometers, pore pressure transducers, LVDTs, and strain gauges. The translation and rocking response of the foundation was monitored using horizontal and vertical accelerometers, respectively. Vertical LVDTs were placed on the four corners of each foundation to measure their permanent settlement and tilt. The total transient inter-story drifts were measured by double integrating the horizontal accelerations at the different floor levels. The different components of total drift (flexural and rocking-induced drift) were separated using the transient foundation rotation measured by vertical accelerometers on the foundation following Karimi and Dashti [23]. Specifically, the total transient roof drift ratio was obtained from the double integration of accelerometer recordings at the roof with respect to the foundation, normalized by the total height of the building. Here, the vertical accelerometers on the two sides of the foundation enabled estimation of the foundation's transient rigid body rotation and hence, the rocking-induced drift. The flexural component of drift was obtained from the difference of total and rocking drift ratios. Fuses were instrumented with strain gauges in a half-bridge configuration on their upper and lower sides to measure their bending strain and moment. Lastly, the centrifuge ambient vibrations before shaking were monitored by all accelerometers (particularly in the far-field) to characterize the small-strain fundamental frequency $\left(\mathrm{f}_{\mathrm{so}}\right)$ of the site, and hence the average site shear wave velocity $\left(\bar{V}_{S}\right)$.

\section{Centrifuge experimental results}

\subsection{Soil response in the far-field}

Fig. 11 summarizes the time histories of excess pore pressure and horizontal acceleration arrays recorded in the far-field during Test 1. Although these sensors were placed at locations away from the structures and container boundaries to the extent possible, some interaction was still expected due to limitations in container size. Hence, this location is referred to as far-field, in order not to imply true "free-field" conditions. The acceleration and pore pressure time histories are compared during Kobe-L, Joshua-H, and Northridge events in Fig. 11. Liquefaction, defined as an excess pore pressure ratio $\left(\mathrm{r}_{\mathrm{u}}\right)$ of 1.0 , was observed quickly in the looser sand layer. Large excess pore pressures were also generated in the lower dense layer of Ottawa sand. The acceleration time histories also showed spikes in the liquefiable layer and at the surface. Larger acceleration spikes were observed as the density of soil increased due to subsequent shaking, which may be attributed to soil dilation and re-stiffening [10], particularly evident during the Northridge event. The relative density of the looser sand layer increased from approximately $40 \%$ prior to Kobe-L (after motion 1) to $66 \%$ prior to the Northridge motion (after motion 3) using the LVDT recordings. 


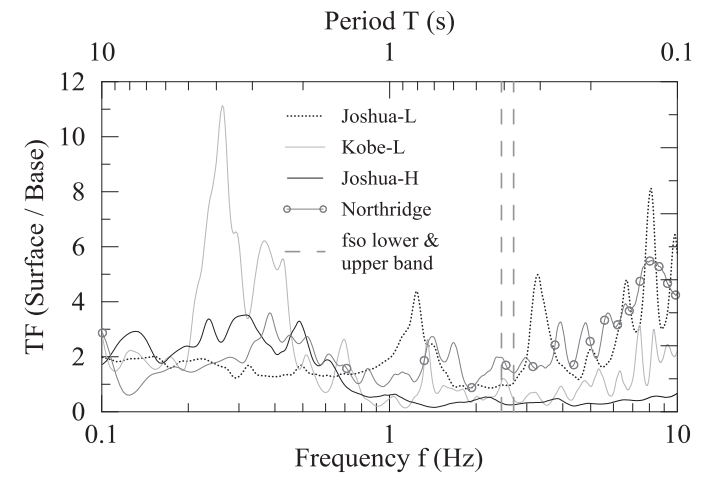

Fig. 12. Transfer function of surface to base accelerations in the far-field during JoshuaL, Kobe-L, Joshua-H and Northridge in Test 1 and the range of small-strain fundamental site frequency based on empirical equations.

The transfer functions (TFs) relating surface to container base accelerations in the far-field are presented in Fig. 12 during a few representative motions to identify, on average, the strain-dependent (effective) fundamental frequency of the site $\left(\mathrm{f}_{\mathrm{so}}{ }^{\prime}\right)$. Even though soil response is highly nonlinear and non-stationary in this case, the use of TFs remains insightful to obtain the $\mathrm{f}_{\mathrm{so}}$ ' in an average sense. The first motion (Joshua-L) that was relatively weak showed a clear peak associated with an effective site fundamental frequency of $\mathrm{f}_{\mathrm{so}}{ }^{\prime} \approx 1.2 \mathrm{~Hz}\left(\mathrm{~T}_{\text {so }}{ }^{\prime} \approx 0.83 \mathrm{~s}\right)$. Since soil significantly softened during the subsequent stronger motions, the frequencies associated with the peak reduced to approximately $0.3-0.4 \mathrm{~Hz}$. The initial (small-strain) fundamental frequency of the site $\left(f_{\mathrm{so}}\right)$ was also estimated using empirical equations for the small-strain shear wave velocity of the soil profile (e.g., [42,4,21,34,15]), which ranged from approximately 176 to $197 \mathrm{~m} / \mathrm{s}$ (corresponding to $\mathrm{f}_{\mathrm{so}}$ ranging from 2.45 to $2.74 \mathrm{~Hz}$, equivalent to $T_{\text {so }}=0.36-0.41 \mathrm{~s}$ ). This variation in estimated $\mathrm{f}_{\mathrm{so}}$ and measured $\mathrm{f}_{\mathrm{so}}{ }^{\prime}$ was expected, since the empirical equations assume very small shear strains.

\subsection{Soil and foundation response in the near-field}

\subsubsection{Properties of the flexible-base structure}

The flexible-base modal period of the structure $\left(\widetilde{T}_{S T}\right)$ without mitigation (Structure A) was obtained in flight under centrifuge ambient vibrations and earthquake motions. Table 2 compares the flexible-base and fixed-base modal periods of Structure A as obtained from different methods. With small strains induced under centrifuge ambient vibrations, the soil underneath Structure A was minimally disturbed and responded within its elastic range and the relative movement between the foundation and soil was negligible. Therefore, modal periods under ambient shaking approached those predicted and measured under fixed-base conditions. As expected, $\widetilde{T}_{S T}$ of the structure increased (lengthened) during stronger motions (e.g., Kobe-L) due to the stiffness degradation of liquefiable soil under Structure A and sliding and rocking of the foundation.

The peak value of transient flexural roof drift was computed as described previously. The base shear demand on the structure at the time corresponding to peak flexural drift was estimated by the sum of the product of masses at different floors and their corresponding accelerations. The resulting peak base shear versus roof drifts measured in Test 1 and 2 on two representative structures (Structures A and A-SW) are compared with the pushover results, as shown in Fig. 7. The measured force-deflection response of these structures in centrifuge aligned well with the elastic range of the pushover results, as expected. This comparison confirms that the overall stiffness and deformation of the model structures were properly represented experimentally in accordance with the design.

\subsubsection{Excess pore water pressures}

Total head isochrones, which were obtained from pore pressure transducer recordings under the center and edge of the foundations as well as the far-field soil are compared in Fig. 13 during the Kobe-L, Joshua-H, and Northridge motions. Consistent with observations in the previous section, far-field isochrones indicated that liquefaction (with the definition of $\mathrm{r}_{\mathrm{u}}=1.0$ ) was achieved rather quickly within the looser layer of Ottawa sand during all motions after Joshua-L. However, liquefaction was often not observed near the structures. Despite the added SFSI-induced cyclic stresses near the edges of the foundation, the increased confining pressure under the center and edge of the foundation resulted in a lower $r_{u}$ than the same soil in the farfield.

The generation of excess pore pressures and flow patterns is a 3D phenomenon influenced by the stress state across the model, dynamic SFSI effects, ground motion characteristics, soil layering, and initial soil properties [10] as well as the mitigation measure employed. For Structure A, hydraulic gradients were generally formed vertically upward. In some cases, a minor horizontal gradient also formed away from the center of the structure. The flow under Structure A-DS was primarily upward. In addition, the looser soil surrounding the structure compared to underneath generated larger excess pore pressures and an inward hydraulic gradient. Under Structures A-DR and A-SW, hydraulic gradients were generally formed upward from the Ottawa dense layer. Slightly smaller excess pore pressures were generated (in terms of the peak values) under the center of Structure A-DR with drains compared to unmitigated Structure A. However, excess pore pressures were kept particularly low around the edges of Structure A-DR due to proximity to drains. The drains led to a consistent outward flow pattern away from the center of this structure. As a result, the duration of large excess pore pressures under Structure A-DR was clearly reduced compared to Structure A.

The response under Structure A-SW was different from the others, because the structural walls around the perimeter constrained shear strains, but also slowed down excess pore pressure dissipation during shaking. The slower dissipation of excess pore pressures and amplification of accelerations within the structural wall resulted in larger net excess pore pressures under this structure, particularly during stronger and longer duration shaking events (e.g., Joshua-H and Northridge). Theoretically, $r_{u}$ values greater than 1.0 are not expected. However, the pore pressure recordings around the edges of Structure A-SW consistently indicated larger $r_{u}$ values than 1.0 at the bottom of the liquefiable layer. These sensors were likely subject to larger vertical stresses from foundation's transient and permanent rotation (as shown in later sections), altering the vertical as well as the horizontal effective stresses near the stiff walls and hence, the capacity for $\Delta \mathrm{u}$ generation. Nevertheless, unlike all the other structures, the soil under the center and edge of Structure-SW experienced liquefaction, which amplified the contribution of volumetric settlements (in particular sedimentation) to its total settlement.

\subsubsection{Foundation settlement}

Fig. 14 compares the settlement time histories at the far-field soil surface and on the building foundations during the Kobe-L and Joshua-H motions. Structure settlement was obtained by averaging the vertical LVDT recordings on the four corners of the foundation. Time histories of $r_{u}$ recorded at the mid-depth of the liquefiable layer beneath the center of each structure and in the far-field as well as the base acceleration are also presented for comparison.

Structures began to settle immediately after the motions began and their settlement became negligible after earthquake loading ceased. Structures (particularly A, without mitigation) settled more than the far-field soil, even though greater values of $r_{u}$ were reached in the farfield. It is difficult to evaluate the contribution of different settlement mechanisms experimentally. However, the underlying mechanics of and the contributing factors to liquefaction-induced building settle- 

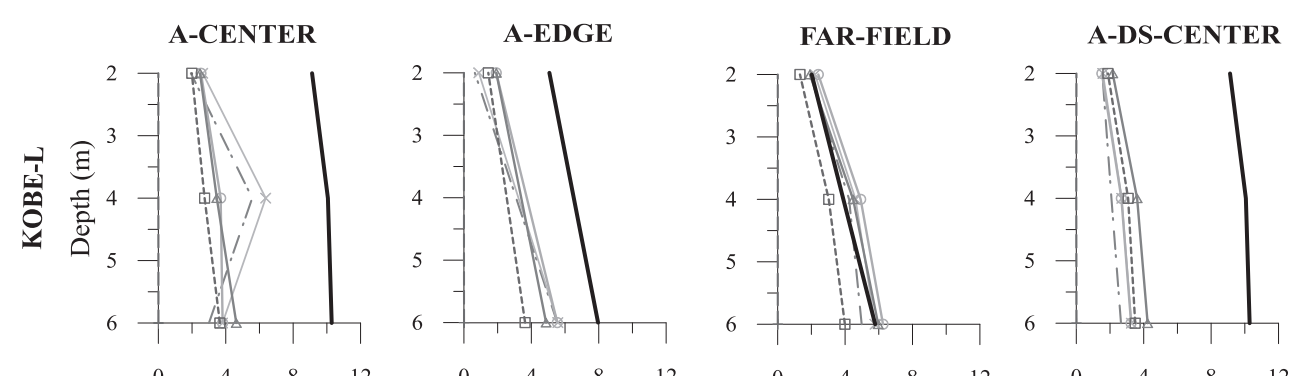

A-DS-EDGE
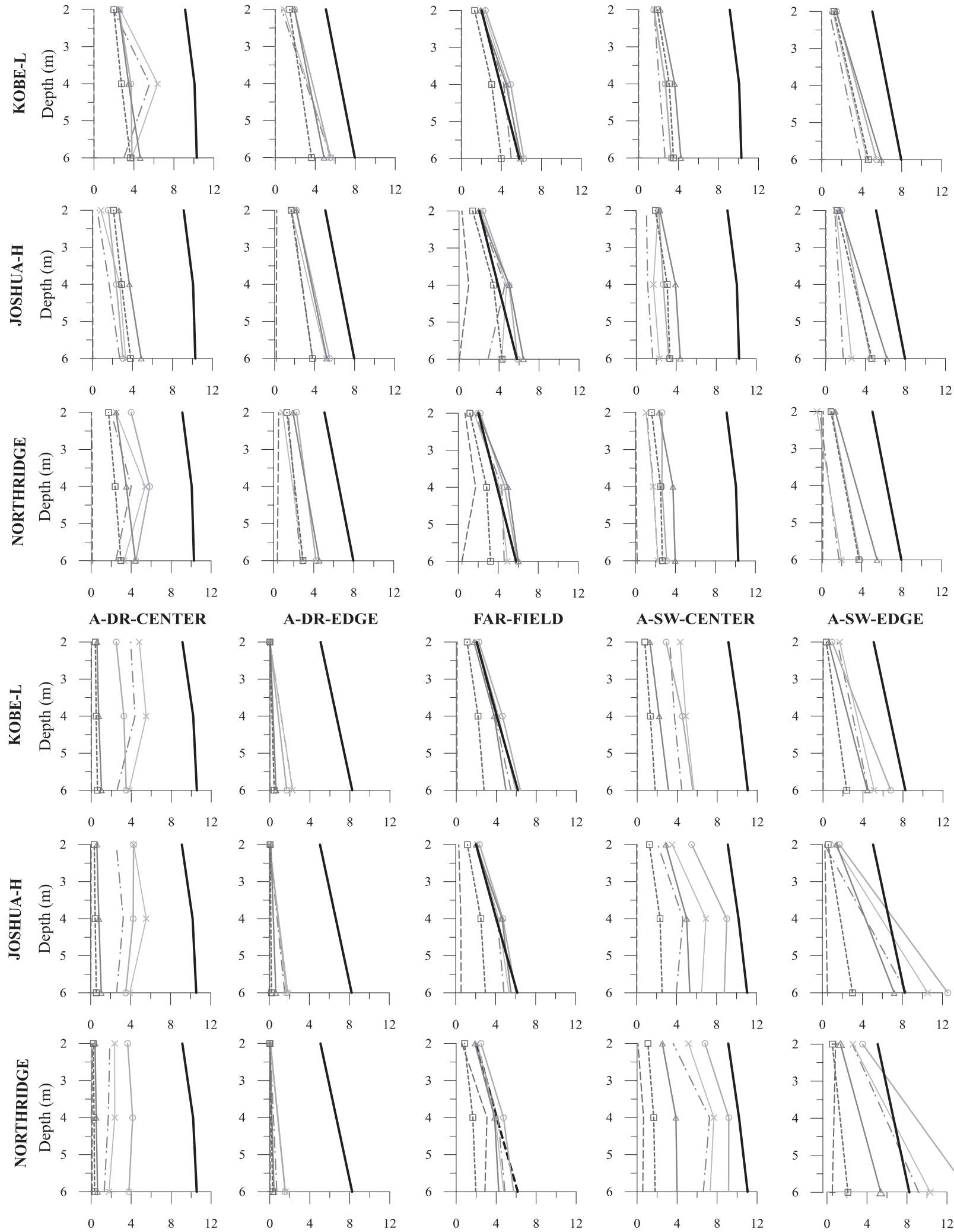

Total Head (m)
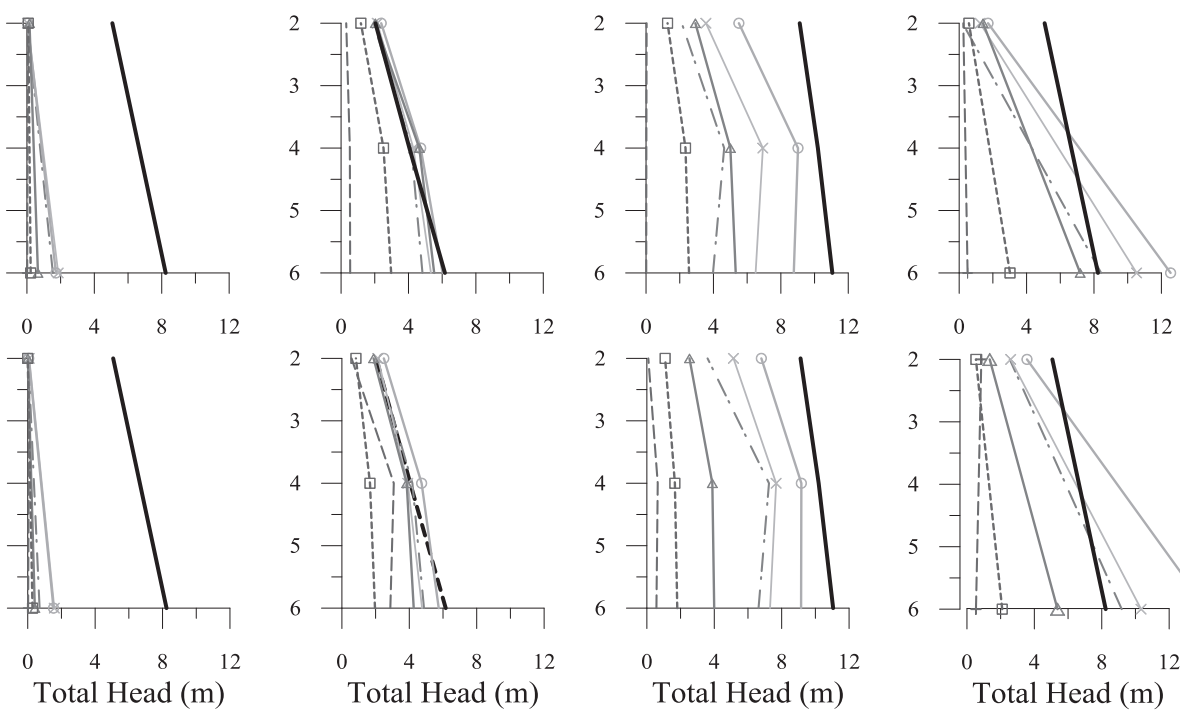

$$
+--+\mathrm{t}=5-\cdots \mathrm{t}=12 \times \times \mathrm{t}=15
$$

$\longleftrightarrow \mathrm{t}=25 \longleftrightarrow \mathrm{t}=100 \quad \square-----\sqsubset \mathrm{t}=200(\mathrm{sec})$

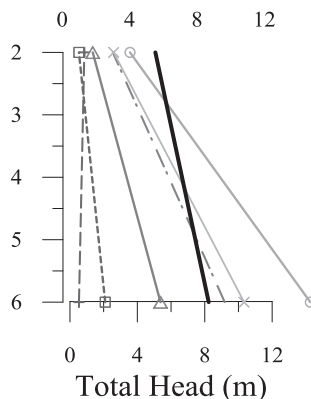

Fig. 13. Total head isochrones measured within the liquefiable layer under the center and edge of the four structures and in the far-field during the Kobe- $\mathrm{L}$, Joshua- $\mathrm{H}$, and Northridge events in both tests. 

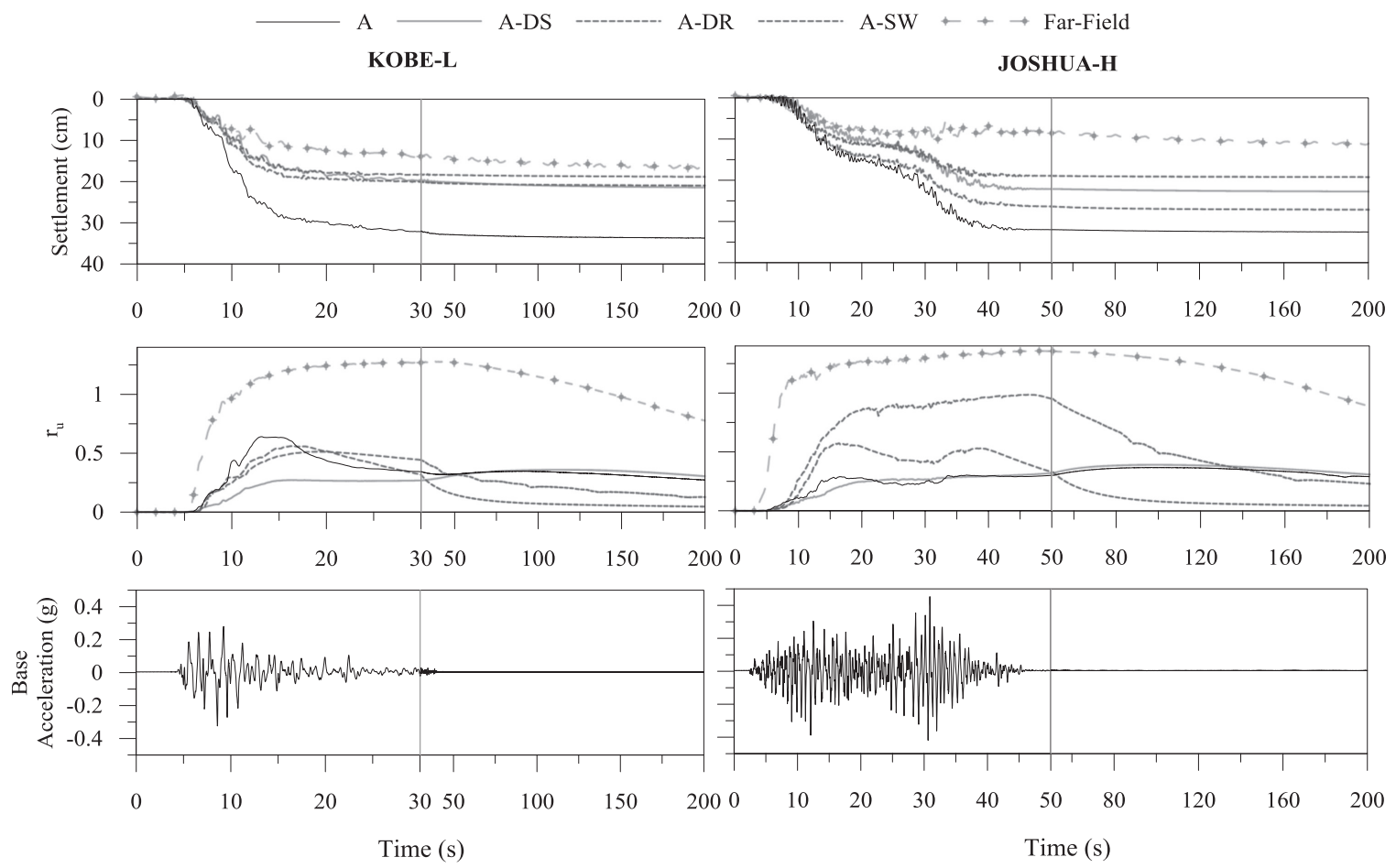

Fig. 14. Time histories of foundation settlement and excess pore pressure ratio in the middle of the liquefiable layer in the far-field and under the center of different structures, in addition to the base acceleration.

ment may help describe the existing trends and differences in the response of different structures. Volumetric strains due to partial drainage $\left(\varepsilon_{p-D R}\right)$ in addition to sedimentation and consolidation $\left(\varepsilon_{p-}\right.$ $S E D$ and $\left.\varepsilon_{p-C O N}\right)$ were responsible for settlements observed in the farfield. The contribution of volumetric strains (in particular $\varepsilon_{p-S E D}$ ) to total settlements under structures reduced, because liquefaction was generally not observed under the foundation (with the exception of Structure SW). Shear type deformations of the soil associated with static and cyclic loading of the structures $\left(\varepsilon_{q-B C}\right.$ and $\left.\varepsilon_{q-S S I}\right)$ contributed to the additional settlements observed under the structures, as evidenced by the deformation of colored sand columns.

Since the baseline structure (A) was founded on looser sand with no mitigation, settlements were significantly greater for this structure compared to others, particularly during the Kobe-L motion (before changes in soil properties due to successive shaking). Structure A's total settlement was similar during Kobe-L and Joshua-H (approximately $35 \mathrm{~cm}$ in both motions, as shown in Fig. 14), even though excess pore pressures generated under its foundation were greater during the Kobe-L motion due to a looser initial soil condition. Larger excess pore pressures under Structure A in Kobe-L led to greater strength loss in the soil, which amplified shear type deformations (mainly $\varepsilon_{q-B C}$ ) as well as volumetric strains due to drainage $\left(\varepsilon_{p-D R}\right)$. However, cumulative shaking intensity and duration were greater during the Joshua- $\mathrm{H}$ motion, amplifying most deformation mechanisms, leading to roughly similar total settlements during the two motions. The rates of foundation settlement were, however, quite different during the two motions, due to the differences in the rate of earthquake energy build-up (see Fig. 10).

Larger net excess pore pressures were developed under Structure A compared to Structure A-DS during the Kobe-L motion, but the extent of pore pressure generation under the two structures became similar after the first significant motion, when considerable volumetric and shear strains were already accumulated in the relatively thin liquefiable layer under Structure A. Similarly, the settlement of Structure A was greater than Structure A-DS initially, during the first motion (Kobe-L). However, a smaller difference was observed during the subsequent motions. Note that in a few cases, an increase in net excess pore pressures was observed within the looser layer of Ottawa sand after shaking ceased, which was due to upward flow from the lower dense layer.

The settlement response of Structures A-DR and A-SW was similar to that of A-DS during the Kobe-L motion (and less than Structure A). During the later motions, Structure A-DR generally experienced larger excess pore pressures in its underlying soil, but they dissipated more rapidly than other cases because of the presence of the vertical drains. The shorter duration of strength loss under this structure in most cases led to smaller shear deformations and smaller net building settlements. Excess pore pressures under Structure A-SW could not dissipate effectively, leading to larger net $r_{u}$ values. In fact, liquefaction $\left(r_{u}=1.0\right)$ was observed under Structure A-SW during the more intense and longer duration Joshua-H motion. Hence, the contribution of $\varepsilon_{p-}$ $S E D$ was amplified, while $\varepsilon_{p-D R}, \varepsilon_{q-B C}$, and $\varepsilon_{q-S S I}$ were lessened by reducing horizontal flow and shear deformations in the looser layer under Structure A-SW. The net effect of different deformation mechanisms for the type of structure, soil profile, and ground motions considered was an increase in total settlements under Structure ASW compared to the other mitigated structures during stronger shaking (i.e., when $\varepsilon_{p-S E D}$ was active under A-SW), but still a reduction in total settlements compared to Structure A with no mitigation.

\subsubsection{Foundation acceleration and rocking}

Transfer functions (TFs) relating foundation to far-field horizontal accelerations are compared on the various structures during a few representative motions in Fig. 15, in order to evaluate the influence of kinematic and inertial interaction on foundation accelerations and the influence of the various mitigation techniques. During the low intensity event (Joshua-L), the TFs mostly approached unity, implying similar accelerations on the foundation and in the far-field soil. During the Kobe-L motion, the greatest amplification of horizontal foundation accelerations was observed near a frequency of 1.0-1.2 Hz (periods of $0.8-1 \mathrm{~s}$ ), which was near the flexible-base fundamental frequency of the structures (Table 2). This amplification in foundation accelerations, likely associated with inertial interaction, was particularly strong for 


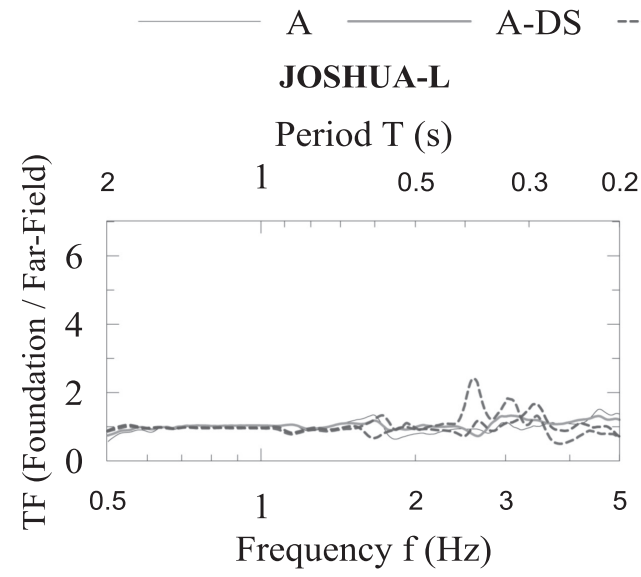

JOSHUA-H

Period T (s)

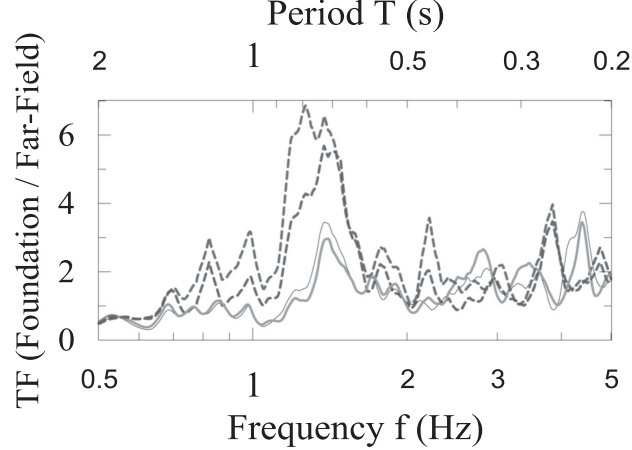

A-DR

\section{KOBE-L}

Period T (s)

\section{A-SW}

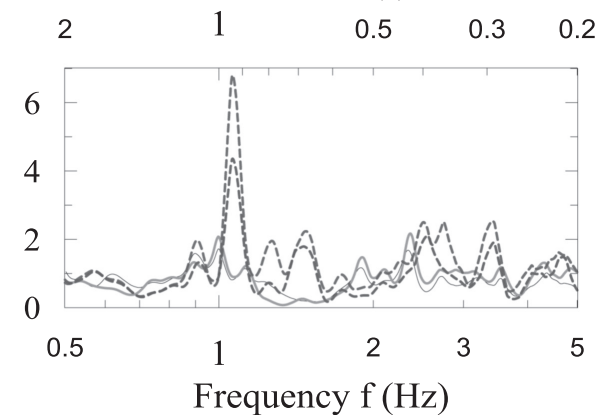

NORTHRIDGE

Period T (s)

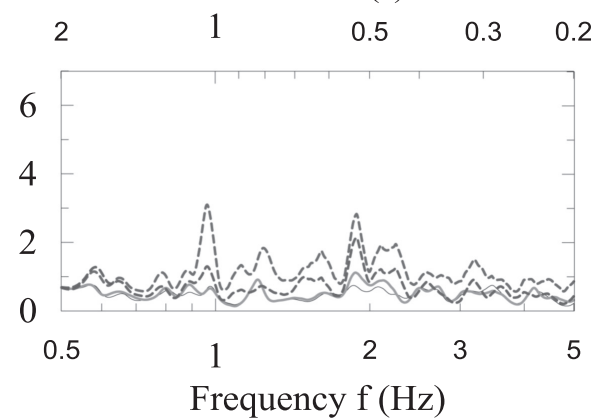

Fig. 15. Transfer functions of foundation to far-field accelerations during the Joshua-L, Kobe-L, Joshua-H, and Northridge events.
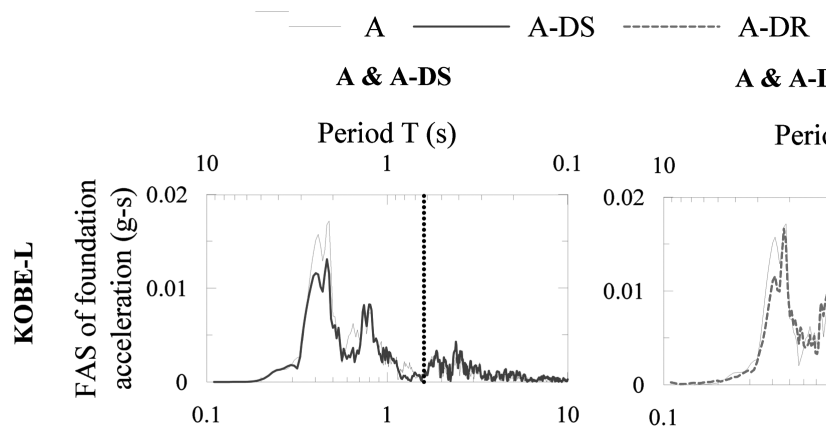

A \& A-DR

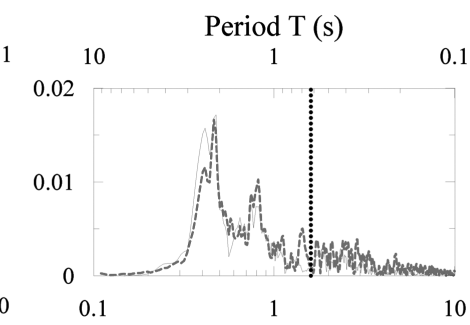

0.1
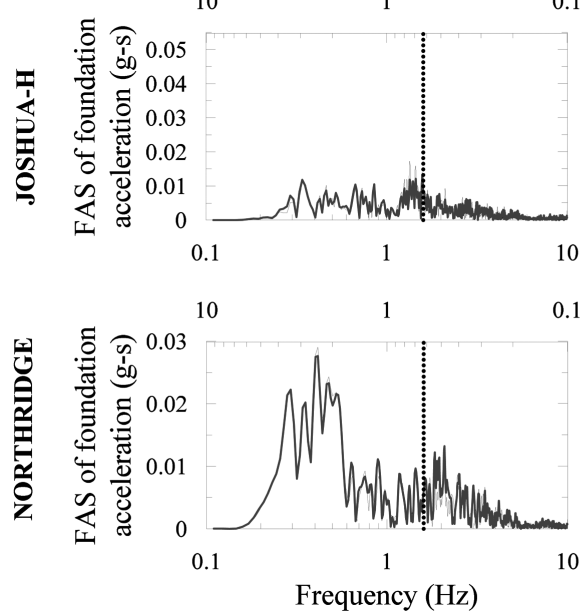

10.1
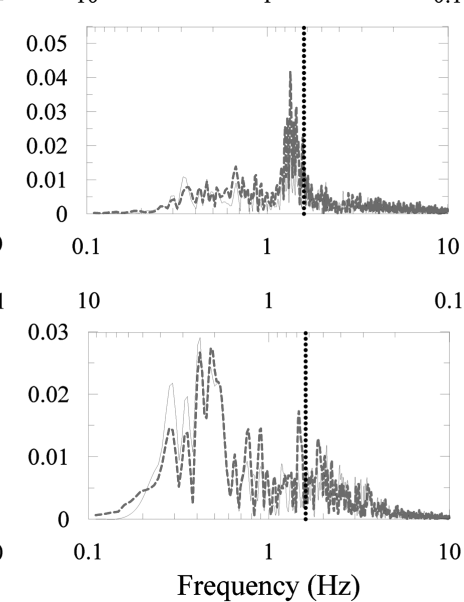

0.1
A-SW

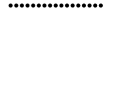

Fixed-base frequency

A \& A-SW

0.1
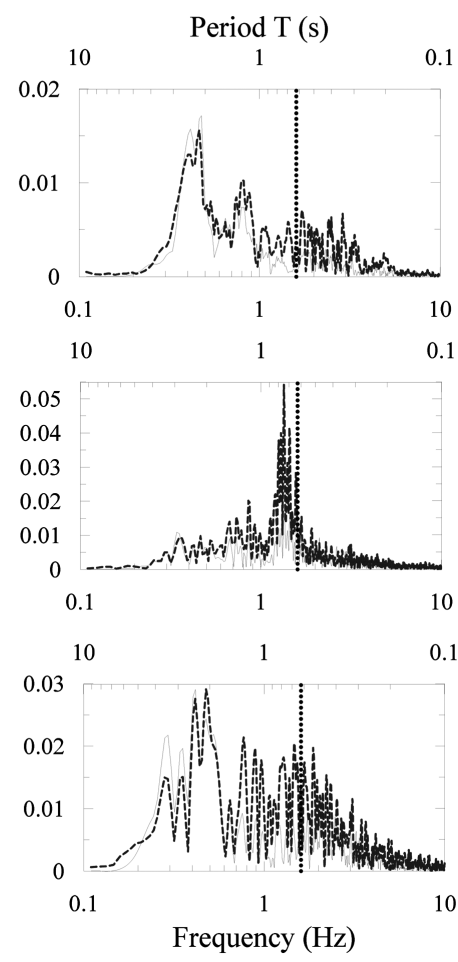

Fig. 16. Fourier amplitude spectra (FAS) of translational accelerations recorded on the foundation during the Kobe-L, Joshua-H, and Northridge events. 
A-DR

A-SW

Rocking fundamental frequency

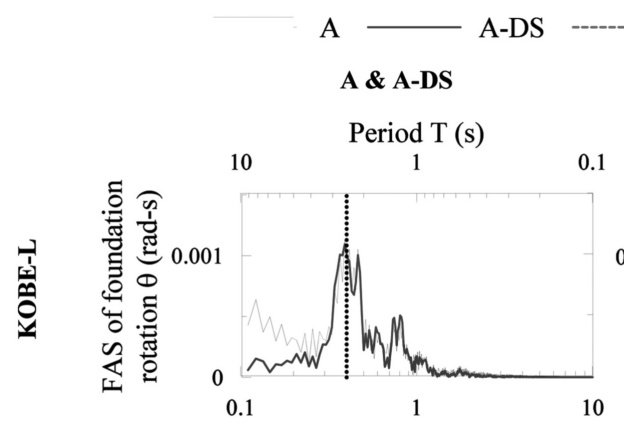

A \& A-DS
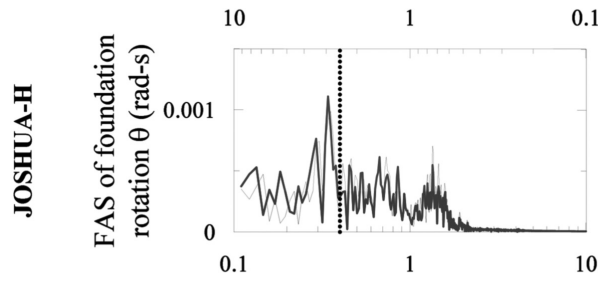

10

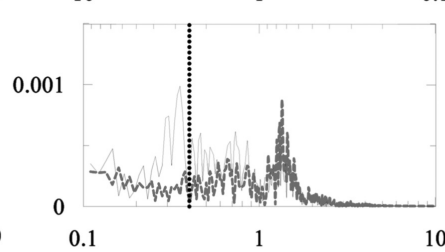

Period T (s)

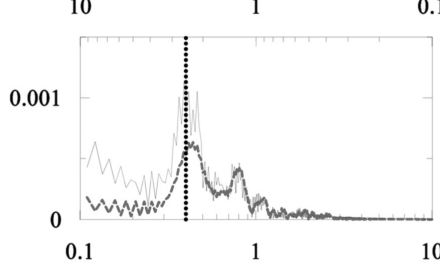

10

0.1

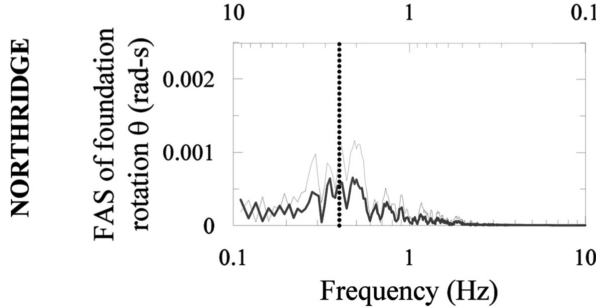

0.1

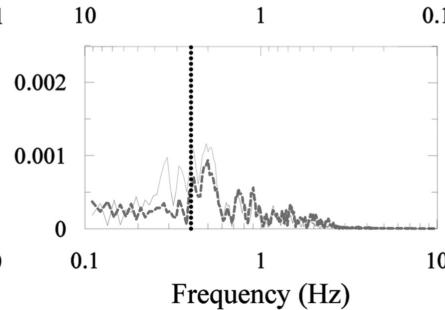

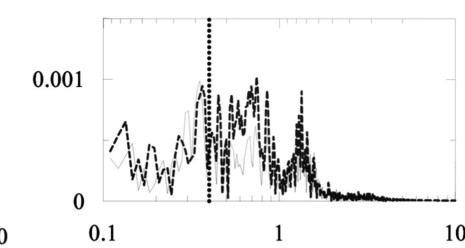

A \& A-SW

Period T (s)

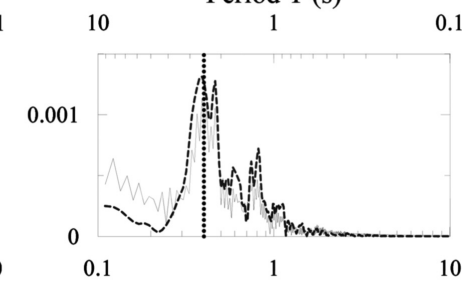

0.1

0.1

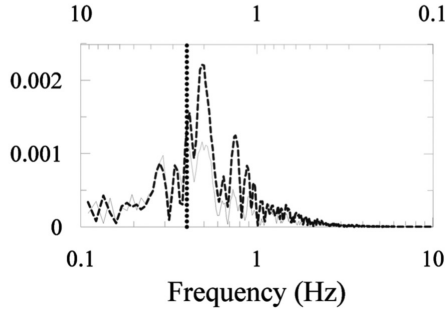

Fig. 17. Fourier amplitude spectra (FAS) of foundation rotation during the Kobe-L, Joshua-H, and Northridge events.

A

A-DS

A \& A-DS
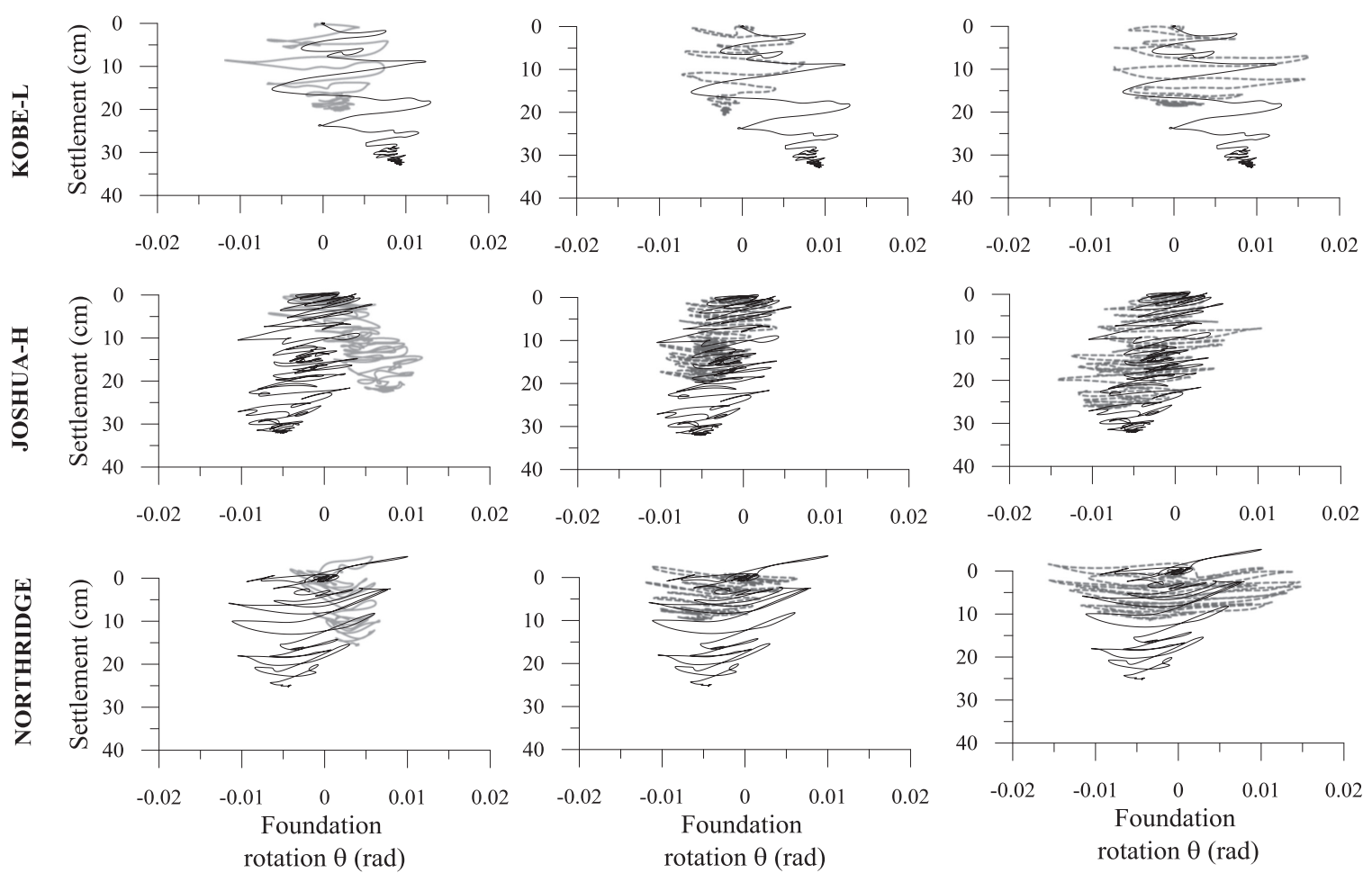

Fig. 18. Foundation settlement and rotation during the Kobe-L, Joshua- $\mathrm{H}$ and Northridge events. 
Structures A-DR and SW, which all constrained the underlying soil from freely deforming.

The Fourier Amplitude Spectra (FAS) of translational accelerations (parallel to the foundation surface) are shown in Fig. 16 for different structures and ground motions. The translational accelerations on Structures A and A-DS were mostly similar for the conditions evaluated in this study. However, the presence of the drains or structural walls often led to greater accelerations transmitted to the foundation, particularly during stronger motions. This amplification was most apparent near the flexible-base fundamental frequency of the structure $\left(\widetilde{f}_{S T o} \approx 1.2 \mathrm{~Hz}, \widetilde{T}_{S T o} \approx 0.83 \mathrm{~s}\right)$. Foundation accelerations also often showed an important content around $0.4 \mathrm{~Hz}$, which is near the effective fundamental frequency of the site in the far-field $\left(f_{\text {so }}{ }^{\prime}\right)$ during the stronger motions (after Kobe-L), as shown previously in Fig. 12. In general, acceleration amplification patterns from the container base toward the soil surface were roughly consistent in the far-field and under the structure without mitigation.

The difference in average LVDT recordings on the north and south ends of the foundation divided by the foundation width provided its rotation - or tilt - as a function of time. When examining the FAS of foundation tilt, Fig. 17 reveals greater foundation rotation on Structure A at lower frequencies compared to the other structures, as expected. The fundamental rocking frequency of the foundation was estimated to be near $0.4-0.5 \mathrm{~Hz}$ for most structures, which was near the far-field site $\mathrm{f}_{\text {so }}{ }^{\prime}$. This trend points to the important influence of site response and resonance on the accelerations and rocking behavior of structures founded on liquefiable soil deposits.

Fig. 18 compares the foundation rotation versus settlement of the baseline Structure A with the other three mitigated structures during the Kobe-L, Joshua-H, and Northridge events. During Kobe-L, the soil underneath Structure A experienced large shear and volumetric strains, leading to large settlements and permanent rotations. After this first major motion, permanent rotation of foundations A and A-DS became more similar in magnitude. All three mitigation techniques tended to reduce residual (permanent) foundation rotation during the less intense motion (Kobe-L), but not necessarily the transient rotation. Structure A-SW in particular experienced large transient foundation rotations, which was likely the result of larger excess pore pressures generated under this structure in addition to amplified accelerations because of the confinement and stiffness provided by the in-ground structural walls. The PVDs around Structure A-DR were particularly effective in reducing transient and permanent foundation tilt as well as settlement, by decreasing the duration and magnitude of large excess pore pressures under the foundation and hence limiting shear type deformations $\left(\varepsilon_{\mathrm{q}-\mathrm{BC}}\right.$ and $\left.\varepsilon_{\mathrm{q}-\mathrm{SSI}}\right)$.

The cumulative permanent rotation and settlement response of each structure during different ground motions is shown in Fig. 19. The cumulative settlement and rotation of Structure A was generally larger

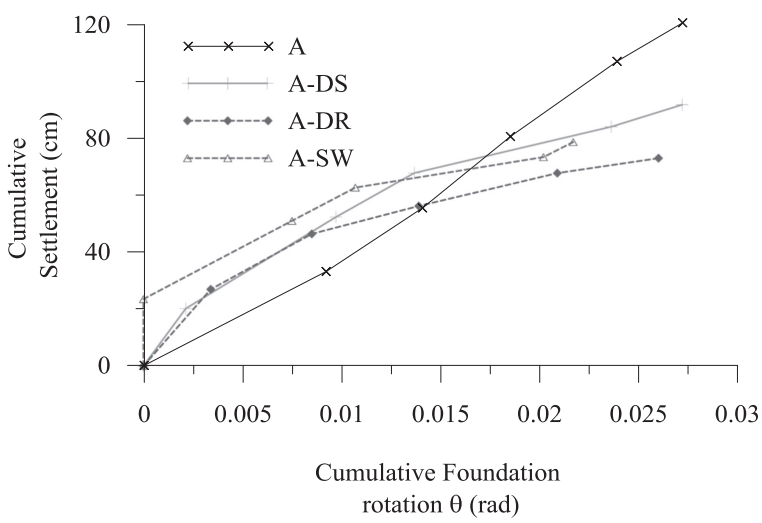

Fig. 19. Cumulative (permanent) settlement and rotation of the foundation during all the different motions applied. compared to the mitigated structures, particularly during the first few motions. This response is associated with large deviatoric and volumetric strains accumulated under this structure, particularly when the soil underneath was looser. Structure A-SW experienced the smallest cumulative permanent foundation rotation (particularly during Kobe-L with approximately no permanent rotation), because the stiff in-ground structural wall provided additional confinement and restriction to shear strains and permanent rotation. However, transient foundation rotations were in fact amplified on this structure. Overall, Structure ADR performed best in terms of both transient and permanent foundation rotation and settlement.

\subsection{Response of the superstructure}

Response of the superstructure is quantified experimentally in terms of roof and interstory drift ratios (relative horizontal displacement normalized by story or roof height) and floor accelerations. These demand parameters are known to be highly correlated with damage to structural and nonstructural components in buildings (e.g., [36]). To compute drifts when evaluating the performance of a building founded on liquefiable ground, one must consider the transient and permanent rigid body rotation (due to tilt or rocking) of the structure separately from the flexural drift that is associated with building deformation.

Time histories of roof total, rocking, and flexural roof drift ratios during the Kobe-L and Joshua-H motions are compared for the structure with no mitigation and the other three structures in Fig. 20. In Kobe-L, slightly greater seismic energy was transferred to the structure when the ground was densified (A-DS) or confined (ASW) compared to the case with no mitigation (A) or with prefabricated vertical drains (A-DR). This greater energy did not get translated into larger transient foundation rotations for Structure A-DS, so a greater demand was transferred to the superstructure of A-DS in the form of flexural drift compared to other structures. On the other hand, transient rocking drifts were significantly amplified on Structure-SW, damping some of the energy transferred to the superstructure and reducing flexural drift. The response of Structure A-DR was roughly similar to that of A during Kobe-L.

During the next motion (Joshua-H), which was more intense and of longer duration, the response of Structure A-DS approached that of A, since the soil under the unmitigated structure (A) had densified and undergone large shear deformations during the first strong motion. The magnitude of total drift on Structures A-SW and A-DR were similar to A. However, A-DR generally experienced a greater high-frequency content in the drift time history, due to the drains limiting the extent of pore pressure generation and its duration in the underlying soil. The transient rocking drifts were slightly reduced on Structure A-DR by limiting liquefaction, while they were amplified on Structure A-SW due to the occurrence of liquefaction in the foundation soil. The net effect was a slight increase in flexural drift on Structure A-DR and a decrease on A-SW compared to the unmitigated case of A. The successful performance of Structure A-DR in terms of reduced total settlement and foundation rotation in this case noticeably amplified the seismic demand on the superstructure and its flexural drift demand throughout shaking.

Roof acceleration response spectra (5\% damped) on different structures during the Kobe-L, Joshua-H, and Northridge events are compared in Fig. 21. Roof spectral accelerations of the baseline, unmitigated Structure A were repeatedly smaller than all other structures during all motions at periods less than approximately $3 \mathrm{~s}$ $(0.33 \mathrm{~Hz})$. This may be explained by Structure A's larger foundation settlement and tilt, which damped out some of the seismic energy transferred to the superstructure. The greatest amplification in roof spectra of A-DS, A-DR and A-SW was observed near the fundamental frequency of the structure $\left(\mathrm{f}_{\mathrm{STo}}\right)$ that ranged from approximately 1.2 to $1.6 \mathrm{~Hz}$ ( $\mathrm{T}_{\mathrm{STo}}$ from 0.6 to $0.83 \mathrm{~s}$ ) for a fixed and flexible base. This amplification was most significant on Structures A-DR and A-SW. The 


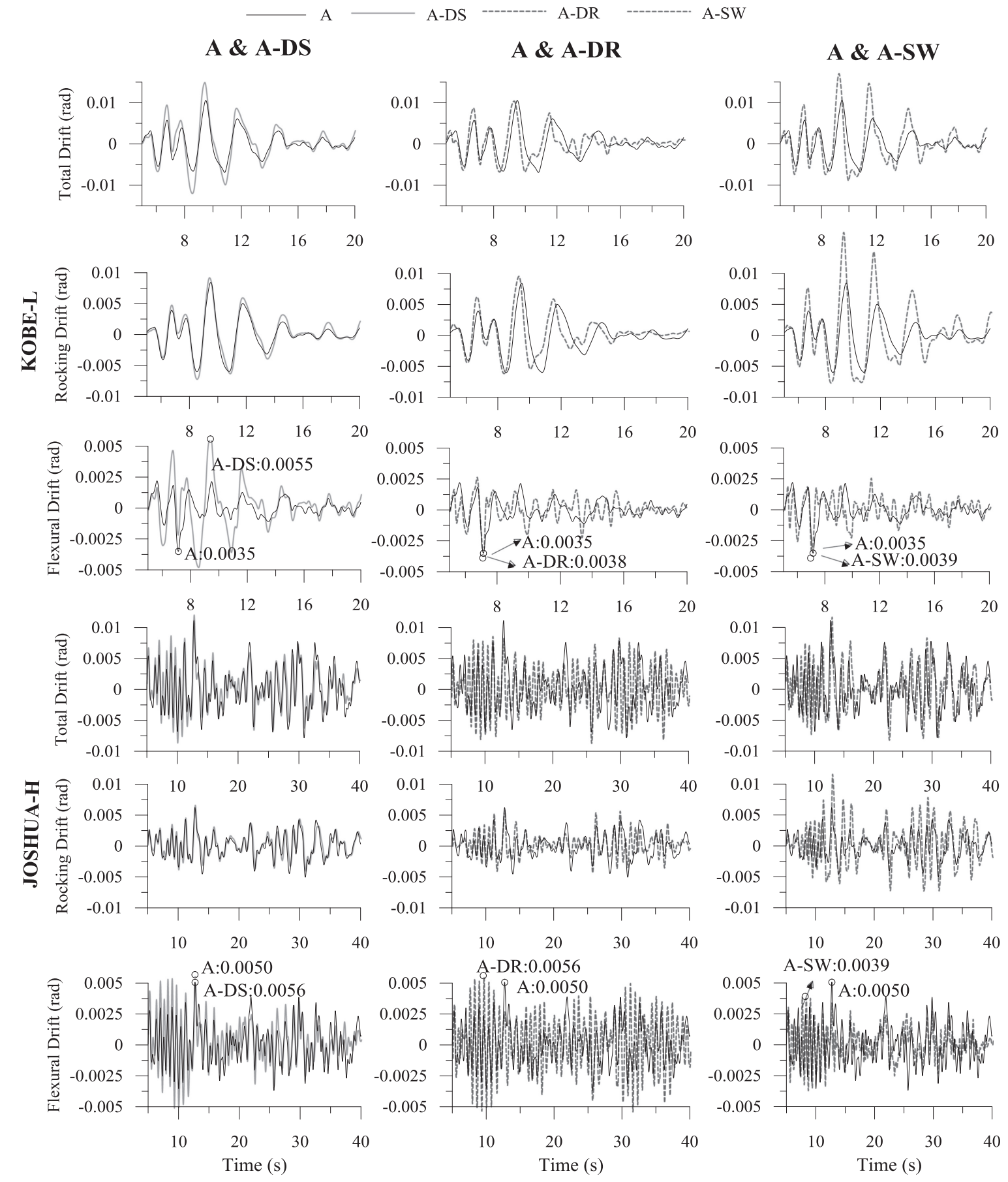

Fig. 20. Total, rocking, and flexural roof drift ratios during the Kobe-L and Joshua-H events. The maximum absolute values of the flexural drift ratios are also noted on the figure.

drains amplified the seismic demand on the superstructure because less energy was dissipated through settlement and tilt (consistent with Fig. 20). Structure A-SW also showed large accelerations on the roof, particularly at lower periods (higher frequencies), likely due to the confinement and rigidity of the structural wall surrounding its foundation, which amplified both foundation (Fig. 15) and roof accelerations particularly at higher frequencies. However, because the foundation transient rotation was also amplified on Structure A-SW, this increase in roof acceleration did not lead to larger flexural drifts in the superstructure (Fig. 20).

The structure was designed according to the "strong-column-weakbeam" criteria and capacity design principles and thus, was expected to experience maximum moments near the beam ends and column bases. In the scaled model, these locations were represented by "fuses" designed to concentrate the larger deformations, as detailed earlier. In this study, only the elastic response of fuses was considered, because the yield strength of the structure was not reached. Even though the fuses did not pass the yield point into the elasto-plastic region, the comparison of the response of MDOF structures, with more realistic force-deformation behavior than previous experimental studies, provides valuable insights into the effectiveness of remediation strategies in terms of building performance.

The moment-rotation behavior of the column fuses was measured using strain gauges and accelerometers and compared with OpenSees analysis results, as shown in Fig. 22 for the Kobe-L, Joshua-H, and Northridge motions. The moment acting on the fuse element under pure bending was computed as $\mathrm{M}=\sigma \cdot I / c$, where $\sigma$ and $M$ are the flexural stress and moment, $c$ the perpendicular distance to the neutral axis of the cross section, and $I$ the second moment of area about the neutral 


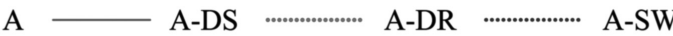 \\ KOBE-L \\ JOSHUA-H}

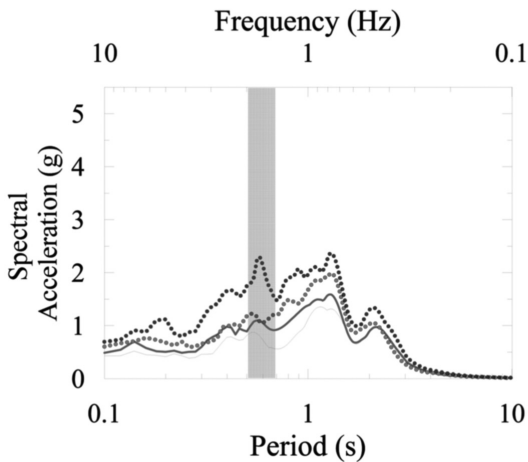

Frequency $(\mathrm{Hz})$

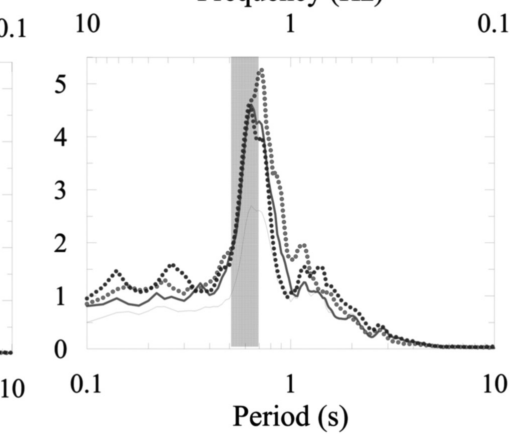

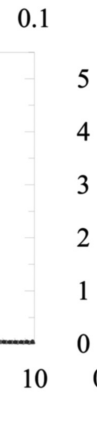

Fundamental frequency of structure

\section{NORTHRIDGE}

Frequency $(\mathrm{Hz})$
0.1

1

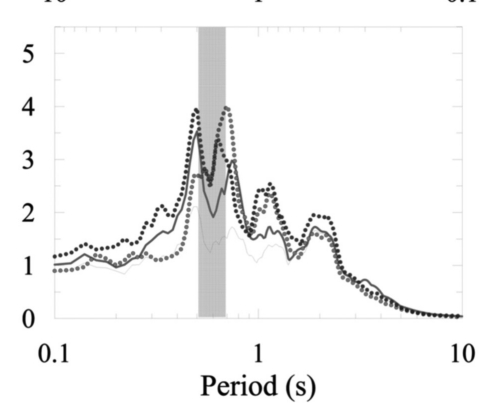

Fig. 21. Horizontal response spectra (5\% damped) of the accelerations recorded on the roof of the structures during the Kobe-L, Joshua-H, and Northridge events.

axis. The stress was obtained by Hooke's law using Young's modulus of steel $(\mathrm{E}=205 \mathrm{GPa})$ and strain gauge recordings. The OpenSees results are based on a two-dimensional (2D) numerical model with linear elastic beam and column elements and concentrated springs at the fuse locations, as discussed earlier.

Structure A-DS experienced slightly larger flexural rotations and moments compared to other structures during the Kobe-L motion, which is consistent with flexural drift measurements in Fig. 20. During the later stronger motions, Structures A-DS and A-DR both slightly amplified the moment and rotation demand on the fuses compared to Structure A. Structure A-SW tended to slightly reduce the momentrotation demand on the fuses compared to other structures. However, in general, the differences in the fuse behavior of different structures presented in this paper were small for the conditions employed. All mitigation strategies were expected to have a more notable effect on settlements, tilts, and drifts when using a thicker liquefiable layer and an inelastic structure, which are currently being examined by the authors.

\section{Concluding remarks}

This paper describes centrifuge experimental design and results to evaluate the influence of liquefaction mitigation on soil and building response and their interaction. The performance of a 3-story steel moment frame structure on a layered liquefiable soil profile was evaluated with three different mitigation techniques (densification,
A $\longrightarrow$ A-DS

A \& A-DS

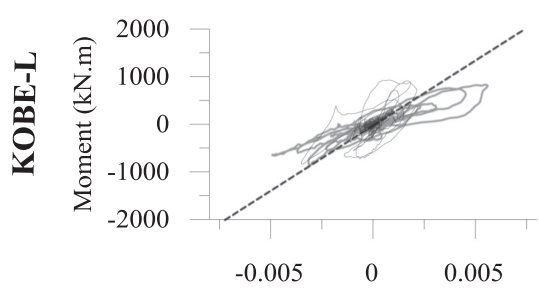

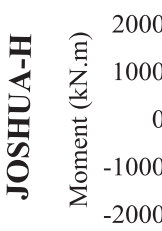

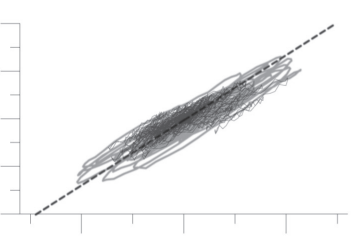

$-0.005$

0

0.005

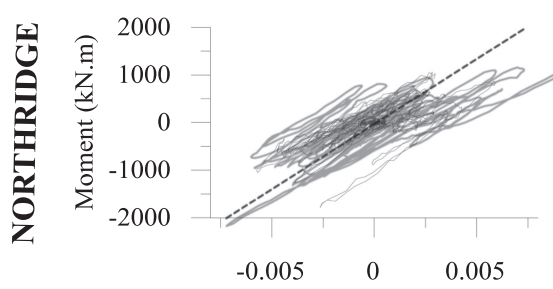

Flexural Drift (rad)
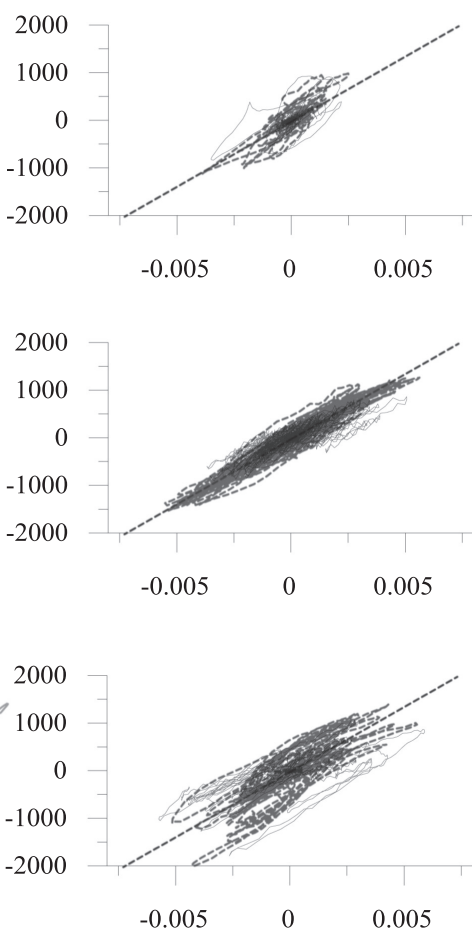

Flexural Drift (rad)
A-SW OpenSees

\section{A \& A-SW}
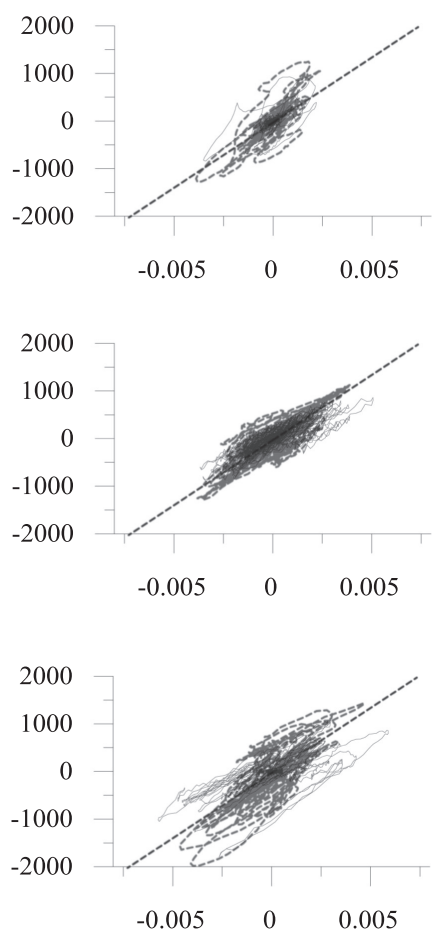

Flexural Drift (rad)

Fig. 22. Moment-rotation hysteretic response from OpenSees and centrifuge experiments during the Kobe-L, Joshua-H, and Northridge events. 
prefabricated vertical drains, and in-ground structural walls) in terms of excess pore water pressures, settlements, and accelerations in the far-field and near-field as well as flexural drift and deformations on "fuses".

Settlement and rotation of the foundation were shown to strongly depend on the drainage conditions, soil properties, and ground motion characteristics. In general, all three mitigation techniques tended to reduce foundation's permanent settlement and tilt. However, the mitigation strategies had differential impacts on the generation of excess pore pressures in the underlying soil, as well as foundation accelerations and transient rotations. These responses influenced the seismic energy transferred to the superstructure and its flexural deformation, wherein larger accelerations and transient rotations were associated with reduced demands on the superstructure and vice versa.

Ground densification slightly reduced excess pore pressure generation as well as permanent foundation settlement and tilt, but tended to slightly amplify the accelerations and forces experienced in the superstructure. Prefabricated vertical drains reduced the duration of large excess pore pressures in the underlying soil, minimizing the permanent and transient foundation settlement and tilt more than other mitigation methods, while amplifying the seismic demand and flexural deformations in the superstructure.

In general, liquefaction (defined as $r_{u}$ near 1.0) was not observed under the confining pressure of the foundation, whereas it was observed rather quickly in the far-field during all motions. Only the soil under Structure A-SW experienced large excess pore pressures and liquefaction during stronger motions, because the structural walls limited flow and amplified accelerations. Larger excess pore pressures and liquefaction in this case amplified the foundation's permanent settlement and tilt compared to other mitigation methods. The amplification of transient foundation rotations in particular damped out some of the seismic demand transferred to the building structure, reducing the moment-rotation demand on the columns and flexural drift.

The centrifuge experimental results presented in this paper show the importance of evaluating in a holistic manner the potential tradeoffs of liquefaction mitigation, which, on the one hand, may reduce foundation settlements and rotations and, on the other hand, may increase ground shaking intensity that result in larger drifts and damage to the superstructure. This understanding is essential for optimizing the design of remediation techniques that focus on performance objectives for the entire soil-structure system. The conclusions and trends discussed in this paper depend on the type of structure, soil profile, and mitigation strategies investigated. Additional configurations are being investigated by the authors both experimentally and numerically, before design recommendations can be made.

\section{Acknowledgments}

This material is based upon work supported in part by the National Science Foundation (NSF) under Grant no. 1362696. Any opinions, findings, and conclusions or recommendations expressed in this material are those of the author(s) and do not necessarily reflect the views of the NSF. The authors would also like to thank Jenny Ramirez Calderon, Simon Petit, Rebecca Scheetz, Luciano D Souza Junior, and Leonardo Soligo Gomes for their assistance in centrifuge model preparation.

\section{References}

[1] Adalier K, Elgamal A. Mitigation of liquefaction and associated ground deformations by stone columns. Eng Geol 2004;72(4):275-91.

[2] American Institute of Steel Construction . Specification for structural steel buildings, 2nd ed.. Chicago, Illinois: American National Standard; 2010.

[3] ASCE . Minimum design loads for buildings and other structures. Reston, Virginia: American Society of Civil Engineers; 2010.

[4] Bardet JP, Huang Q, Chi SW. Verification of numerical procedures for the analysis of soil liquefaction problems. In: Proceedings of verification of numerical procedures for the analysis of soil liquefaction problems '93. Davis, California; 1993.

[5] Bird JF, Bommer JJ. Earthquake losses due to ground failure. J Eng Geol 2004;74(2):147-79.

[6] Bray JD, Stewart JP, Baturay MB, Durgunoglu T, Onalp A, Sancio RB, et al. Damage patterns and foundation performance in Adapazari. Earthq Spectra 2000;16(S1):163-89.

[7] Chen Z, Hutchinson TC, Trombetta NW, Mason HB, Bray JD. Seismic performance assessment in dense urban environments: evaluation of nonlinear buildingfoundation systems using centrifuge tests, In: Proceedings of the fifth international conference on recent advances in geotechnical earthquake engineering and soil dynamics, San Diego, CA; 2010.

[8] Chopra AK. Dynamics of structures: theory and applications to earthquake engineering, 6th ed.. Englewood Cliffs, N.J.: Prentice Hall; 2007.

[9] Cubrinovski M, McCahon I. Short term recovery project 7: CBD foundation damage. Natural Hazards Research Platform. Christchurch, New Zealand: University of Canterbury; 2012.

[10] Dashti S, Bray JD, Pestana JM, Riemer MR, Wilson D. Mechanisms of seismicallyinduced settlement of buildings with shallow foundations on liquefiable soil. J Geotech Geoenviron Eng 2010;136(1):151-64.

[11] Dashti S, Bray JD, Pestana J, Riemer MR, Wilson D. Centrifuge testing to evaluate and mitigate liquefaction-induced building settlement mechanisms. J Geotech Geoenviron Eng 2010;136(7):918-29.

[12] Green RA, Cubrinovski M, Wotherspoon L, Allen J, Bradley B, Bradshaw A, et al. Geotechnical reconnaissance of the 2011 Christchurch, New Zealand earthquake. Geotechnical Extreme Events Reconnaissance (GEER) Report. Vol. 1. 8 November $2001 ; 2011$.

[13] Hamada M, Wakamatsu K, Ando T. Liquefaction-induced ground deformation and its caused damage during the 1995 Hyogoken-Nanbu earthquake. In: Proceedings of the sixth Japan-US workshop on earthquake resistant design of lifeline facilities and countermeasures against soil liquefaction. US National Center for Earthquake Engineering Research (NCEER); 1996. p. 137-52.

[14] Hamburger RO, Krawinkler H, Malley JO, Adan SM. Seismic design of steel special moment frames: a guide for practicing engineers. NEHRP Seismic Design Technical Brief No. 2 (NIST GCR 09-917-3); 2009. p. 2-37.

[15] Hardin BO, Drnevich VP. Shear modulus and damping in soils: measurement and parameter effect. J Soil Mech Found Div 1972;98(6):603-24.

[16] Hausler EA. Influence of ground improvement on settlement and liquefaction: a study based on field case history evidence and dynamic geotechnical centrifuge tests [Ph.D. dissertation]. Berkeley: University of California; 2002.

[17] Hayden RF, Baez JI. State of practice for liquefaction mitigation in North America In: Proceedings of international workshop on remedial treatment of liquefiable soils. Tsukuba City, Japan: Public Works Research Institute; 1994.

[18] Howell R, Rathje EM, Kamai R, Boulanger R. Centrifuge modeling of prefabricated vertical drains for liquefaction remediation. J Geotech Geoenviron Eng 2012;138(3):262-71.

[19] Iai S, Matsunaga Y, Morita T, Miyata M, Sakurai, H, Oishi, H, et al. Effects of remedial measures against liquefaction at 1993 Kushiro-Oki earthquake. In: Proceedings of 5th U.S-Japan workshop on earthquake resistant design of lifeline facilities and countermeasures against soil liquefaction. Technical Rep. NCEER-94$0026 ; 1994$.

[20] Ibarra LF, Medina RA, Krawinkler H. Hysteretic model that incorporates strength and stiffness deterioration. Earthq Eng Struct Dyn 2005;34:1489-511.

[21] Jamiolkowski M, Leroueil S, LoPresti DCF. Theme lecture: design parameters from theory to practice. In: Proceedings of Geo-Coast '91. Yokohama, Japan; 1991. p. 141.

[22] Japanese Geotechnical Society (JGS) . Remedial measures against soil liquefaction. Rotterdam: A.A. Balkema; 1996.

[23] Karimi Z, Dashti S. Seismic performance of structures on liquefiable soils: insight from numerical simulations and centrifuge experiments. J Geotech Geoenviron Eng 2016;142:6.

[24] Ketchum SA. Development of an earthquake motion simulator for centrifuge testing and the dynamic response of a model sand embankment [Ph.D. thesis] USA: University of Colorado Boulder; 1989.

[25] Kimura T, Takemura J, Hiro-oka A, Okamura M, Matsuda T. Countermeasures against liquefaction of sand deposits with structures. In: Ishihara K, editor. Proceedings of the 1st international conference on earthquake geotechnical engineering. Rotterdam, The Netherlands: A.A. Balkema; 1995. p. 1203-24.

[26] Krawinkler H. Guidelines for cyclic seismic testing of components of steel structures. Redwood City, California: Applied Technology Council; 1992.

[27] Krawinkler H, Zohrei M, Lashkari-Irvani B, Cofie N, Hadidi-Tamjed H. Recommendations for experimental studies on the seismic behavior of steel components and materials. John Blame Cent. 61.

[28] Lignos DG, Krawinkler H. Sidesway collapse of deteriorating structural systems under seismic excitations. Report No. 177. John A. Blume earthquake engineering center; 2012.

[29] Lignos DG, Krawinkler H, Whittaker AS. Prediction and validation of sidesway collapse of two scale models of a 4-story steel moment frame. Earthq Eng Struct Dyn 2011;40:807-25.

[30] Liu L, Dobry R. Seismic response of shallow foundation on liquefiable sand. J Geotech Geoenviron Eng 1997;123(6):557-67.

[31] Madabhushi SPG, Haigh SK. Effect of superstructure stiffness on liquefactioninduced failure mechanisms. Int J Geotech Earthq Eng 2010;1:71-87.

[32] Mason HB. Seismic performance assessment in dense urban environments (Ph.D dissertation). Berkeley: Department of Civil and Environmental Engineering, University of California; 2011. 
[33] McCartney JS, Kuhn JA, Zornberg JG. Geosynthetic Drainage layers in contact with unsaturated soils. In: Proceedings of 16th ISSMGE conference on geotechnical engineering in harmony with the global environment. Tokyo, Japan: Ministry of Land, Infrastructure and Transport and the Ministry; 2005.

[34] Menq FY. Dynamic properties of sandy and gravely soils [Ph.D. dissertation]. University of Texas, Austin: Department of Civil and Environmental Engineering; 2003.

[35] Mitchell JK, Wentz Jr FJ. Performance of improved ground during the Loma Prieta earthquake. Earthquake Engineering Research Center. Rep. No. UCB/EERC-91/12, University of California, Berkeley; 1991.

[36] Mitrani-Reiser J, Haselton C, Goulet C, Porter K, Beck J, Deierlein G. Evaluation of the seismic performance of a code-conforming reinforced-concrete frame building - part II: loss estimation. Earthq Eng Struct Dyn 2006;36:1973-97.

[37] Onuce A, Mori N, Takano J. In-situ experiment and analysis on well resistance of gravel drains. Soils Found 1987;27(2):42-60.

[38] Pestana JM, Hunt CE, Goughnour RR. FEQDrain: a finite element computer program for the analysis of the earthquake generation and dissipation of pore water pressure in layered sand deposits with vertical drains. Report No. EERC 97-17 Earthquake Engineering Research Center. University of California, Berkeley; 1997.

[39] Popov EP, Stephen RM. Cyclic loading of full-size steel connections. Center for Cold-Formed Steel Structure Libraries; 1972. 21.

[40] Sancio R, Bray JD, Durgunoglu T, Onalp A. Performance of buildings over liquefiable ground in Adapazari, Turkey. In: Proceedings of the 13th world conference on earthquake engineering. Vancouver, Canada, August 2004, No. 935; 2004.

[41] Seed HB, Booker J. Stabilization of potentially liquefiable sand deposits using gravel drains. J Geotech Eng Div 1997;103(GT7):757-68.

[42] Seed HB, Idriss IM. Soil moduli and damping factors for dynamic response analyses. Report EERC 70-10. Earthquake Engineering Research Center University of California, Berkeley; 1970.

[43] Stewart DP, Chen YR, Kutter BL. Experience with the use of methylcellulose as a viscous pore fluid in centrifuge models. Geotech Test J 1998;21(4):365-9.

[44] Stringer ME, Madabhushi SPG. Novel computer-controlled saturation of dynamic centrifuge models using high viscosity fluids. Geotech Test J 2009;23(6):1-6.

[45] Taylor R. Geotechnical centrifuge technology, 1st ed.. London: Taylor \& Francis; 1995.

[46] Tsai KC. Seismic response of steel reduced beam section to weak panel zone moment joints. In: Proceedings of 3rd international conference STESSA 2000. Montreal, Canada; 2000.

[47] United States Steel (USS), Steel sheet piling design manual, U.S department of transportation, 1984

[48] Wilson E, Habibullah A. Sap 2000 integrated finite element analysis and design of structures basic analysis reference manual. Berkeley, California: Computers and Structures. Inc; 1998.

[49] Yoshimi Y, Tokimatsu K. Settlement of buildings on saturated sand during earthquakes. Soils Found 1977;17(1):23-38. 